\title{
A study of nucleate boiling and critical heat flux with EHD enhancement
}

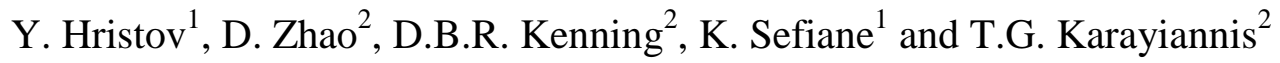 \\ ${ }^{1}$ School of Engineering and Electronics, The University of Edinburgh, Edinburgh EH9 3JL, UK, E-mail: \\ k.sefiane@ed.ac.uk; \\ ${ }^{2}$ School of Engineering and Design, Brunel University, West London, Uxbridge, Middlesex UB8 3PH, UK, \\ E-mail: david.kenning@brunel.ac.uk,tassos.karayiannis@brunel.ac.uk;
}

\begin{abstract}
The paper describes results from an experimental and theoretical study of the effect of an electric field on nucleate boiling and the critical heat flux (CHF) in pool boiling of R123 at atmospheric pressure on a horizontal wall with a smooth surface. Two designs of electrode (parallel rods and wire mesh) were used.

The experimental data exhibit some differences from the data obtained by other researchers in similar experiments on a wall with a different surface finish and with a slightly different design of wire mesh electrode. The hydrodynamic model for EHD enhancement of CHF cannot reconcile the differences.

A theoretical model has been developed for the growth of a single vapour bubble on a superheated wall in an electric field, leading to a numerical simulation based on the level-set method. The model includes matching of sub-models for the micro- and macroregions, conduction in the wall, distortion of the electric field by the bubble, the temperature dependence of electrical properties and free-charge generation. In the present form of the model, some of these effects are realised in an approximate form. The capability to investigate dry-spot formation and wall temperature changes that might lead to CHF has been demonstrated.
\end{abstract}

Key words : Critical heat flux (CHF), Electrohydrodynamics (EHD), pool boiling.

\section{Introduction}

\subsection{Mechanisms of critical heat flux}

In a heat flux -controlled system, increasing the heat flux in the nucleate boiling regime in pool boiling on a horizontal wall leads to an uncontrolled increase in wall temperature due to the onset of film boiling at the critical heat flux. A predictive mechanistic model for CHF of general application has yet to be achieved. The hydrodynamic instability theory, Zuber [1], assumes that film boiling is triggered when the supply of liquid to the wall is impeded by the development of waves at the interfaces between counter-flowing columns of vapour and liquid due to Helmholtz shear instability at a critical vapour velocity. The spacing of the columns is equal to the most-dangerous wavelength, $\lambda_{\mathrm{d}}$, for Taylor instability of a vapour film on a horizontal surface. 
The controlling process in the macro-region implies that the properties of the heated wall and the state of its surface should not affect the CHF. This prediction is supported by some experimental studies but not by others. Haramura and Katto [2], extended the model to include the influence of heater surface finish and contact angle on microlayers at the base of vapour stems in a macrolayer beneath a large vapour mass. Observations of the wall region through transparent walls (which therefore had special surface and thermal properties), e.g. by Nishio et al. [3] and Chung and No [4], showed near to CHF the existence of a fluctuating network of liquid contact zones that maintained cooling. Theofanous et al. [5,6] showed that individual bubbles could maintain their identity at very high heat fluxes; CHF occurred when the transient temperature rise at the dry patches under bubbles was so high that rewetting was prevented. Sefiane et al. [7,8] and Nikolayev et al. [9,10] argued that the recoil forces arising from the momentum change due to intense evaporation in the contact line region would have a large influence on its motion, which could be studied during the growth of bubbles at sub-critical heat fluxes.

\subsection{Micro- and macro-region models}

Wayner et al. [11] initiated a long series of theoretical and experimental studies of evaporation near the contact line of perfectly wetting liquids on smooth walls. The contact "line" is actually a zone of width of order $10^{-7} \mathrm{~m}$, where there is intensely high heat transfer due to the extremely thin liquid film, in which the conventional thermofluid equations are modified by the attractive forces of the wall. The high heat fluxes make it necessary to modify the conventional assumption of local equilibrium at the liquid-vapour interface. Stephan and Hammer [12] developed a model for bubble growth that incorporated these requirements in a micro-region model for lubrication flow in the thin liquid film and the temperature field in the wall close to the contact zone. This has evolved into a methodology for numerical simulation of bubble growth by matching the micro-region model to a macro-region model that solves the Navier-Stokes and convective energy equations in the liquid surrounding a growing, non-spherical bubble. Son et al. [13] tracked the evolving liquid-vapour interface in the macro region by the level-set method, which assumes a continuous variation in thermodynamic properties across a thin interfacial zone. The method has been extended from the modelling of single bubbles with axial symmetry to complex situations such as the coalescence of up to three bubbles [14], the sort of process that may occur during the approach to CHF. There are concerns about the accuracy of the level-set method and limitations imposed by the computational grid, e.g. on initial bubble size and resolution of the wall temperature field near the moving contact zone. The contact zone model does not at present address the general situation of finite equilibrium contact angle on a rough surface. Mathieu et al. $[15,16]$ have discussed convection in the micro-region for zero and finite contact angle.

\subsection{EHD enhancement of boiling}


Electrohydrodynamics (EHD), in which a strong electrostatic field is imposed on a slightly electrically conductive fluid, has been recognised as an efficient active method to augment heat exchange, reviewed by Allen and Karayiannis [17]. Potential advantages include the tuning of heat exchanger capacity by varying the applied electric field, the ability to meet demand that was not envisaged at the design stage and the substitution of electrical forces for buoyancy as a mechanism for moving vapour away from the heated surface during pool boiling in microgravity [18]. Enhancement of pool nucleate boiling heat transfer coefficients by up to $900 \%$ has been reported for refrigerants in normal gravity, Ohadi et al. [19]. Nucleation is enhanced, vapour bubbles detach from the superheated wall at a much smaller size and higher frequency and move violently around on the wall, e.g. Ogata and Yabe [20]. Markels and Durfee [21] found that the CHF was increased by up to $500 \%$ by applying $8 \mathrm{kV}$ DC to semi-insulating liquid systems such as isopropyl alcohol.

The electrohydrodynamic body force per unit volume [22] is given by

$$
\mathbf{F}_{E}=\rho_{e} \mathbf{E}-\frac{1}{2} E^{2} \nabla \varepsilon+\frac{1}{2} \nabla\left(E^{2} \rho \frac{\partial \varepsilon}{\partial \rho}\right),
$$

in which the local electric field strength $E$ depends on the geometries of the heated surface and the electrodes, the presence of bubbles and temperature gradients that affect local values of electrical permittivity and conductivity. It is found from the Poisson equation for the electric potential

$$
\nabla \cdot(\varepsilon \mathbf{E})=-\rho_{e}
$$

The free charge density $\rho_{\mathrm{e}}$ in the bulk fluid is found from the equation for conservation of charge, assuming $\varepsilon$ and $\sigma_{e}$ are functions only of temperature,

$$
\left(\frac{\varepsilon}{\sigma_{e}}\right) \frac{\partial \rho_{e}}{\partial t}+\rho_{e}=\varepsilon \mathbf{E} \cdot\left[\frac{\nabla \varepsilon}{\varepsilon}-\frac{\nabla \sigma_{\mathrm{e}}}{\sigma_{e}}\right]=\varepsilon \mathbf{E} \cdot \nabla T\left[\frac{1}{\varepsilon} \frac{d \varepsilon}{d T}-\frac{1}{\sigma_{e}} \frac{d \sigma_{e}}{d T}\right]
$$

which may be written as

$$
\tau \frac{\partial \rho_{e}}{\partial t}+\rho_{e}=\frac{\varepsilon \mathbf{E} \cdot}{\tau} \nabla \tau
$$

where $\tau=\varepsilon / \sigma_{\mathrm{e}}$, the charge relaxation time. Free charges are generated in regions of varying electrical permittivity and conductivity, across liquid-vapour interfaces and in thermal boundary layers near heated walls and growing vapour bubbles. Free charges are neglected in models that treat the liquid as a pure dielectric with $\sigma_{\mathrm{e}}=0$ but this is a questionable assumption for many liquids used in boiling systems. Zaghdoudi and Lallemand [23] calculated the steady, creeping electroconvection around a bubble immersed uniform electric field for all ratios of the permittivity and conductivity in the liquid and vapour. For transient 
processes in liquids with finite electrical conductivity, it is generally argued that the accumulation of free charges on the interfaces of bubbles requires that the charge relaxation time of the liquid be small compared to the characteristic time for processes such as bubble growth and detachment. Some typical values for $\tau$ for liquids boiling at atmospheric pressure taken from recent papers [23-26] are given in Table 1. They are often quoted from one reference to the next and are rarely measured in boiling experiments. A practical difficulty is the sensitivity of the electrical conductivity to contamination and this may account for some discrepancies between quoted values of $\tau$ and between experiments comparing the effects of electric fields on boiling for different fluids. $\mathrm{Xu}$ [27] measured the electrical conductivity of samples of R123 from a pool boiling rig in which condensate was returned continuously to the boiling chamber through a filter-drier. Subjecting samples drawn from the chamber to an additional passage through a filter-drier reduced $\sigma_{\mathrm{e}}$ by $22 \%$, although its coefficient of change with temperature was unaltered.

Karayianis [28] reported experiments on pool boiling of R123 and R11 on a horizontal bundle of five $19 \mathrm{~mm}$ tubes with rod electrodes at potentials up to $25 \mathrm{kV}$ and low heat fluxes up to $20 \mathrm{~kW} / \mathrm{m}^{2}$. With R11, in which free charge effects are expected to be negligible, the enhancement by the electric field was only marginal. With R123, heat transfer coefficients were increased by factors of up to 9.3 at $5 \mathrm{~kW} / \mathrm{m}^{2}$ and $25 \mathrm{kV}$. The enhancement decreased with increasing heat flux. There are variations in behaviour, depending on electrode configuration and the position of the tube in the bundle: Karayiannis and $\mathrm{Xu}[29,30]$ suggested that the electric field promoted the sliding of bubbles in close contact with the tubes due to a combination of the size and direction of the electric forces on the bubbles. The hypothesis was supported by numerical calculations of the electric fields and forces on bubbles with uniform arrays of static truncated spherical bubbles on the tubes, immersed in a steady thermal boundary layer to generate free charges. Multiple layers of bubbles reduced the forces on the bubbles closest to the wall. Oh and Kwak [25] performed pool boiling experiments with R11, R113 and FC-72 on a single $19 \mathrm{~mm}$ tube at heat fluxes up to about $50 \mathrm{~kW} / \mathrm{m}^{2}$ provided by an internal flow of hot water, with 6 wire electrodes at potentials up to $15 \mathrm{kV}$. By contrast with [29,30], heat transfer coefficients for R11 were enhanced by factors of up to 2.3. There was slightly greater enhancement for R113 at very low wall superheats, with no effect at wall superheat above $13 \mathrm{~K}$, corresponding to heat fluxes above $20-25 \mathrm{~kW} / \mathrm{m}^{2}$. The electric field had no effect at all on the boiling of FC-72, which has the longest relaxation time (see Table 1).

Uemura et al. [31] performed experiments over a much wider range of heat flux up to a maximum CHF of $300 \mathrm{~kW} / \mathrm{m}^{2}$ with R113 in saturated pool boiling at atmospheric pressure on the plane surface of a $40 \times 40 \mathrm{~mm}$ copper block at angles of $0^{\circ}, 90^{\circ}$ and $180^{\circ}$ to the horizontal. The field was provided by a potential of up to 35 $\mathrm{kV}$ applied to a mesh of $0.5 \mathrm{~mm}$ wires at $1.7 \mathrm{~mm}$ square spacing at a distance of $10 \mathrm{~mm}$ from the heated surface, which should have given a much more uniform field (in the absence of bubbles) than in the 
experiments on tubes. In the horizontal position, there were large ratios of enhancement of heat transfer at low heat fluxes but the boiling curves for different potentials converged at higher fluxes above $10 \mathrm{~kW} / \mathrm{m}^{2}$. Increasing the potential extended the boiling curve to higher values of $\mathrm{CHF}$, which was increased by a factor of 2.2 at $35 \mathrm{kV}$. At $90^{\circ}$ and $180^{\circ}$, there was greater enhancement extending throughout the nucleate boiling range up to $\mathrm{CHF}$, which was also increased. Zaghdoudi and Lallemand [24] performed experiments for similar conditions in saturated pool boiling at atmospheric pressure on a horizontal copper plate $30 \mathrm{~mm}$ diameter with a mesh electrode ( $2 \mathrm{~mm}$ square separation, 54\% free area) at a distance of $10 \mathrm{~mm}$ from the plate with R113, n-pentane and R123. As in [31], they observed enhancement of nucleate boiling heat transfer coefficients that increased almost linearly with the electric potential but decreased with increasing heat flux. The diminishing effect at higher heat flux, i.e. with more detached bubbles between the electrode and the heated wall, is consistent with the finding of Karayiannis and $\mathrm{Xu}$ [29] that detached bubbles weaken the effective field strength and the forces on bubbles at the wall. Nucleate boiling is expected to depend on surface variables such as roughness; according to the hydrodynamic model, CHF should not be affected. The surface in [24] was polished with No. 600 grade emery paper; the preparation in [31] was not specified. The values of CHF for R113 at 0 and $25 \mathrm{kV}$ potential were $232 \mathrm{~kW} / \mathrm{m}^{2}$ and $285 \mathrm{~kW} / \mathrm{m}^{2}$ respectively (ratio 1.2) in [24], $143 \mathrm{~kW} / \mathrm{m}^{2}$ and $223 \mathrm{~kW} / \mathrm{m}^{2}$ (ratio 1.5) in [31]. Possible reasons for the differences are surface conditions, the small differences in geometry and the effect of differences in the electrical conductivity of the $\mathrm{R} 113$ on the charge relaxation time. As electric fields facilitate nucleation, enhancement at low wall superheats might be sensitive to the availability of nucleation sites. Compared to R113 and n-pentane, R123 exhibited inception of boiling at lower wall superheat (even without an electric field) and substantially higher enhancement of the heat transfer coefficients, particularly at low heat fluxes. The values of CHF without an electrical field were similar for R123 $\left(240 \mathrm{~kW} / \mathrm{m}^{2}\right)$ and R113 $\left(232 \mathrm{~kW} / \mathrm{m}^{2}\right)$ but application of $25 \mathrm{kV}$ caused increases to $594 \mathrm{~kW} / \mathrm{m}^{2}$ (ratio 2.5) for R123 and only $285 \mathrm{~kW} / \mathrm{m}^{2}$ (ratio 1.2) for R113. This indicates a strong dependence of the enhancement on the electrical conductivity and hence the charge relaxation time, since these are the only properties of the fluids that differ significantly, Table 1.

Zaghdoudi and Lallemand [24] defined two electric influence numbers relating to nucleate boiling

$$
\begin{aligned}
& E l=\frac{\rho_{l}\left(d \varepsilon_{l} / d T\right) d^{2} \Delta T E^{2}}{\mu_{l}^{2}}, \text { where the characteristic length } d=\left(\frac{\sigma}{\left(\rho_{l}-\rho_{v}\right) g}\right)^{1 / 2} \\
& E l^{\prime}=\frac{\rho_{l} \tau\left(d \sigma_{e} / d T\right) d^{2} \Delta T E^{2}}{\mu_{l}^{2}}, \text { where the charge relaxation time } \tau=\varepsilon_{l} / \sigma_{e}
\end{aligned}
$$

Following the work of Ahsman and Kronig [32] and Bonjour et al. [33], they sought a correlation for the increase in Nusselt number $\mathrm{Nu}$ due to the electric field in insulating fluids

$$
N u(E)-N u(0)=\Delta N u=A[E l \cdot \operatorname{Pr}]^{\bar{p}},
$$


where $A$ and $\bar{p}$ are empirical constants. The form of the correlation ensures that the enhancement ratio decreases as the heat flux increases. With this correlation, the data for R123 formed a distinct group from the data for R113 and n-pentane. Zaghdoudi and Lallemand stated that substituting $E l^{\prime}$ for $E l$ in the correlation brought all their data onto a single line with the same values of $A$ and $\bar{p}$ for the three fluids but they did not show the final result.

Zhagdoudi and Lallemand found that hydrodynamic models for CHF that were modified to include the effect of an electric field in reducing the most dangerous wavelength for Helmholtz instability, e.g. Johnson [34] and Berghmans [35], led to expressions for enhancement of the form $q_{c r}(E) / q_{c r}(0)=F\left(E l^{*}\right)$, where

$$
E l^{*}=\frac{B E^{2}}{\left[3\left(\rho_{l}-\rho_{v}\right) \sigma g\right]^{1 / 2}}
$$

and $B$ is a function only of the permittivities of the liquid and vapour phases that depends on the particular assumptions in the model, Table 2 [24]. Johnson [34] modelled waves at a plane interface between two perfectly insulating fluids in a uniform electric field calculated as though only homogeneous fluid were present between the electrodes. Berghmans [35] modelled the CHF during pool boiling on a large horizontal cylindrical heater, assuming that the vapour was a perfect insulator and the liquid was a perfect conductor, so the permittivity of the liquid did not feature in the model. There was one adjustable parameter, the thickness of the macrolayer pierced by parallel columns of liquid and vapour, empirically set to $1.0-1.5 \mathrm{~mm}$. The permittivity of the vapour is usually assumed equal to the permittivity of a vacuum, $\varepsilon_{0}$. The model of Lovenguth and Hanesan [36] depended on the permittivity of the liquid. All the expressions predict an initial nonlinear increase in $q_{c r}(E) / q_{c r}(0)$ with $E$, followed by a linear increase at high field strengths. Zhagdoudi and Lallemand found that their data fitted the trend predicted by [36] but that it was necessary to introduce an empirical correction to the values of $B$, which they attributed to departures of the local field strength from the assumed nominal uniform value. (They did not comment on the possible influence of the charge relaxation time $\tau$, as in the nucleate boiling region). The correction factors calculated from their property values in Table 1 were 1.7 for R123 and only 0.27 for R113 and 0.25 for n-pentane.

It is clear from the above selective examples that the hydrodynamic model for CHF is inadequate. Issues requiring further examination are

(i) Nonuniformity of the electric field due to electrode geometry and bubbles, including the passage of bubbles through electrode assemblies. 
(ii) Modification of the field by the temperature dependence of electrical properties.

(iii) Electrical conductivity and charge relaxation, including experimental control of liquid properties.

(iv) The influence of processes in the micro-region at the heated wall.

Some of these issues can be examined through the study of individual bubbles.

\subsection{Studies of a single bubble in an electric field.}

Bubble growth on a solid wall in boiling has been modelled experimentally and theoretically by the formation of gas bubbles at an orifice in isothermal liquid under conditions of constant volumetric flow, in normal gravity and with comparative studies in varying degrees of microgravity. This work has been summarized in a recent paper by Iacona et al. [37] and extended to the coalescence of bubbles from adjacent nozzles by Liu et al. [38]. Herman and Iacona [39] developed an approximate model that successfully matched the departure shapes for air injected into PF5052 in a uniform electric field, which has a short charge relaxation time of $1.2 \mathrm{~ms}$ for a dielectric fluid, compared to $155 \mathrm{~s}$ for FC-72. The model combined the Cheng-Chaddock [40] model for quasi-static detachment of an ellipsoidal bubble with the Kumar-Kaloor [41] model for bubbly flow from an orifice with viscous drag and buoyancy, but not inertia. Because of the absence of inertia, a force field (residual gravity or electric) was necessary for detachment. The ChengChaddock model requires as input an experimental "contact angle" remote from the wall, beyond the region of necking, so it is an artefact of the local flow field and not a material property. Cho et al. [42] computed the equilibrium shape of a gas bubble of specified volume, attached to a wall in combined uniform electrical and gravitational fields in a perfect dielectric liquid without bulk free charges. It was necessary to specify either the contact angle or the contact radius. Di Marco et al. [43], in experiments in very low microgravity, found that bubbles only detached at higher flow rates, indicating the significance of inertial forces.

Injection experiments demonstrate the influence of field geometry on bubble shape. In the approximately uniform field generated by a plane electrode above a plane wall, Herman and Iacona [39] observed the predicted elongation of the bubbles in the direction of the field. In the non-uniform field created by a small spherical electrode placed off-axis from the orifice, which might simulate the distortion of the field by detached bubbles in boiling, bubbles were elongated and tilted [37,38]. Di Marco et al. [43] injected bubbles from an orifice in the side of a $1 \mathrm{~mm}$ diameter tube surrounded by a cage of 8 rod electrodes. The field strength near the tube was calculated to vary inversely with radial distance. For the maximum electrode voltage of $15 \mathrm{kV}$, the field strength varied from about $5.1 \mathrm{MV} / \mathrm{m}$ to $1.7 \mathrm{MV} / \mathrm{m}$ over the bubble departure diameter. Under these conditions, there is no indication of elongation when the images in [43] are magnified.

By their nature, isothermal injection experiments do not include the effects of temperature-dependent electrical properties in large temperature gradients or intensive evaporation at a moving contact line with 
large inertial stresses that are characteristic of boiling at pressures well below the Critical Pressure. There do not yet appear to have been numerical studies of bubble growth in an electric field of the sort performed by Son et al. [13] for vapour bubbles in a gravitational field.

\subsection{This investigation}

The paper describes results from a combined experimental and theoretical study of the effect of an electric field on the critical heat flux in pool boiling of R123 at atmospheric pressure on a horizontal wall with a smooth surface and two designs of electrode (parallel rods and wire mesh). R123 was chosen because it demonstrated strong enhancement by an electric field in the experiments of Karayiannis [28] and Zaghdoudi and Lallemand [24]. The experimental conditions are similar to those of Zaghdoudi and Lallemand, except for a smoother surface finish and a slightly different design of wire mesh electrode, placed closer to the wall. It will be shown that these apparently minor changes may be responsible for significant differences in the data.

In the theoretical study, a numerical simulation has been developed for the growth of a single vapour bubble on a superheated wall in an electric field, based on the level-set method of Son et al. [13]. The model includes matching of models for the micro- and macro- regions, conduction in the wall, distortion of the electric field outside and inside the bubble, the temperature dependence of electrical properties and freecharge generation. In the present form of the model, some of these effects are realised in an approximate form, because of limitations imposed by the numerical stability of iterative loops, which will be resolved in due course. The simulation for the micro-region in the vicinity of the moving contact line has been realised in MATLAB. The simulation in the macro-region has been based on the commercial CFD code COMSOL Multiphysics, with the code converted to MATLAB for iterative matching with the micro-region model.

\section{Experimental facility}

The experimental set-up consisted of a boiling chamber, heating system, condenser and cooling plant, high voltage supply, control and measurement facility, Fig. 1. The system operated as a thermosyphon with the refrigerant condensing in the heat exchanger located above the chamber. The condensate returned to the boiling chamber via a filter/dryer. The condenser was cooled by circulating water chilled by a R-134a refrigeration system. The rectangular boiling chamber made of $12 \mathrm{~mm}$-thick mild steel accommodated the working fluid, heating block, electrode and temperature sensors. A refrigerant charging inlet, liquid and vapour thermocouples, a pressure relief valve, a pressure transducer and a pressure gauge were all positioned on the topside of the chamber and the heating block, the high voltage connector and the refrigerant outlet were located on the bottom plate. Two windows $20 \mathrm{~mm}$ x $90 \mathrm{~mm}$ were located at the front and back of the 
chamber. The boiling process took place on the $40 \mathrm{~mm}$ square top surface of an oxygen-free copper block 50 $\mathrm{mm}$ long. The sides of the block were insulated with Teflon. Three $750 \mathrm{~W}$ electric cartridge heaters, diameter $9.5 \mathrm{~mm}$ and length $31.8 \mathrm{~mm}$, were embedded in the bottom of the block. The voltage input to the heaters was controlled by a variable transformer and the power input was measured by a power meter. The temperature gradient in the copper block was measured with uncertainty $0.5 \mathrm{~K}$ by four $1 \mathrm{~mm}$ stainless steel sheathed $\mathrm{K}$ type thermocouples inserted $15 \mathrm{~mm}$ deep and located 3.0, 8.4, 12.7 and $18.0 \mathrm{~mm}$ from the heating surface with uncertainty $0.5 \mathrm{~mm}$. The temperature field inside the copper block was assumed one-dimensional and the heat flux was calculated from the temperature gradient with maximum uncertainty of approximately $5 \%$ for $\mathrm{CHF}$ and $15 \%$ for nucleate boiling. The maximum error in heat transfer coefficient was around $5 \%$ at $\mathrm{CHF}$ and $16 \%$ for nucleate boiling at very low heat flux.

The boiling surface was prepared as follows. Firstly, the milled copper surface was polished with emery paper P1200 which was attached on the base of a steel block with a weight of $12 \mathrm{~N}$. Confined between two guides, the block was moved on the heating surface from front to back and then sideways, 50 times in each direction. After every 50 movements the emery paper was renewed and the whole procedure repeated. Next, the surface was treated by the same procedure, using ultra-fine abrasive paper (particle size $\sim 3$ micrometers) from 3M Company. Nitrogen was blown on the polished surface to remove all the particles. Finally, the copper surface was protected by a cover until it was installed into the boiling chamber.

The electric field was generated by a high-voltage DC power supply (Model AU-30P3.3 Matsusoda Precision Inc) that provided voltages of up to $30 \mathrm{kV}$, positive with respect to the earthed test surface. In order to create a non-uniform electric field, the rod electrode configuration shown in Fig. 2a was used. The electrode consisted of nine parallel $1.56 \mathrm{~mm}$ rods soldered in a $77 \mathrm{~mm}$ x $77 \mathrm{~mm}$ frame. A more uniform electric field was created by using the mesh electrode, also formed of $1.56 \mathrm{~mm}$ wire with the same $54 \%$ free area as in [24], shown in Fig. 2b. The electrode frames were mounted in the slots of two Teflon insulation plates at the same distance of $5 \mathrm{~mm}$ above the surface in all the tests.

\section{EXPERIMENTAL PROCEDURE}

The boiling chamber and condenser system were first filled with nitrogen to 1 bar gauge pressure to check for leaks. After the system was leak free, the boiling chamber was evacuated to eliminate non-condensable gases. Liquid R123 was then passed through the filter/dryer into the vessel until the liquid-vapour interface was $80 \mathrm{~mm}$ above the heat transfer surface. The working fluid was boiled at a moderate heat flux for 30 minutes to remove any remaining trapped air. The non-condensable gas trapped in the top part of the condenser was vented to the atmosphere. The system pressure was governed by adjusting the circulating water flow rate in the condenser. All the experiments were carried out at 1 bar absolute pressure. Boiling 
curves were obtained by increasing the heat flux. Data, including current and voltage measurements, thermocouple readings, and the vessel pressure, were logged after steady conditions were reached, indicated by the measured liquid temperature remaining constant at the saturation value corresponding to the system pressure of 1 bar for $10 \mathrm{~min}$.

Tests with increasing and decreasing heat flux did not reveal the well-documented hysteresis phenomenon, Fig. 3. The boiling curves were therefore obtained by gradually increasing the heat flux with a constant voltage applied to the electrode until the approach to CHF was detected through the sudden increase of the wall temperature. Many factors including the boiling surface finish, the size of the heater and the physical properties of the liquid such as contact angle may affect the development of hysteresis in the boiling curve. Auracher and Marquardt [44] reported that no hysteresis was shown on boiling curves in steady state conditions with FC-72 (small contact angle fluid) and distilled water (large contact angle liquid). The working fluid was renewed after each set of experiments for a boiling curve was completed, in case the electrical fluid properties of R123, in particular its electrical conductivity, might have changed after being boiled for some time, Yamashita and Yabe [45]. A slight deposit on the boiling surface can substantially shift the boiling curve and increase CHF, Auracher and Marquardt [44]. Any change in surface conditions was monitored by checking the reproducibility of a particular set of zero-field conditions after the measurement of each complete boiling curve. If the superheat at a heat flux of $89 \mathrm{~kW} / \mathrm{m}^{2}$ changed by more than $1 \mathrm{~K}$ from previous measurements, the surface was removed and repolished. The long-term reproducibility is illustrated in Fig. 4. Changes are within the estimated experimental uncertainty, except at very low heat fluxes in nucleate boiling. In this case, the maximum uncertainty is around $10 \%$ for low fluxes in nucleate boiling and $5 \%$ for the CHF. Although the relative uncertainty for nucleate boiling is much greater than that for the CHF, the absolute error given by the error bar for low heat flux is too small to be seen in Fig. 4 .

\section{Experimental data and discussion}

\subsection{Data}

Boiling curves were measured at zero field voltage, then at voltages increasing in $5 \mathrm{kV}$ steps from $10 \mathrm{kV}$ to $25 \mathrm{kV}$ for the rod electrodes and for the mesh electrode. The present results are compared with the data of Zaghdoudi and Lallemand [24] for the same fluid and a similar geometry, but with the surface of the copper wall finished with much coarser 600 grade emery paper and a mesh electrode of the same free area set at the greater height of $10 \mathrm{~mm}$ instead of $5 \mathrm{~mm}$. For the same applied voltage, the nominal field strength in [24] is half the field strength in the present work. 
The boiling curves for the rod electrodes are shown in Fig. 5(a). The application of the lowest voltage of 10 $\mathrm{kV}$ causes a reduction in wall superheat of about $5 \mathrm{~K}$ at a given heat flux and a $46 \%$ increase in the critical heat flux. Further increases in voltage have less effect at heat fluxes below $200 \mathrm{~kW} / \mathrm{m}^{2}$. When expressed as a ratio of heat transfer coefficients with and without an electrical field, it can be seen that the effect of a given field is smaller at higher heat fluxes, Fig. 6(a). Deviations in the effect of increasing voltage start to appear at a heat flux of about $320 \mathrm{~kW} / \mathrm{m}^{2}$, Fig. 5(a). At $15 \mathrm{kV}$, the slope of the boiling curve is reduced as the CHF of $330 \mathrm{~kW} / \mathrm{m}^{2}$ is approached. At $20 \mathrm{kV}$, there is a small increase in slope before starting to level off towards the CHF of $415 \mathrm{~kW} / \mathrm{m}^{2}$. At $25 \mathrm{kV}$, there is a marked increase in slope, which is maintained to a much higher heat flux before levelling off towards the CHF of $646 \mathrm{~kW} / \mathrm{m}^{2}$. The boiling curves for the mesh electrode are shown in Fig. 5(b) and representative curves for the two electrode geometries are compared in Fig. 5(c). At $15 \mathrm{kV}$, the wall superheat for a given heat flux is about $1 \mathrm{~K}$ higher for the mesh electrode and the CHF is slightly lower. At $25 \mathrm{kV}$, the wall superheat is less than $1 \mathrm{~K}$ higher than for the rod electrodes up to the heat flux at which there is a marked increase in the slope of the boiling curve for the rod electrodes. The increase in slope is much smaller for the mesh electrode and the CHF of $418 \mathrm{~kW} / \mathrm{m}^{2}$ is reached shortly afterwards (compared to $646 \mathrm{~kW} / \mathrm{m}^{2}$ for the rod electrodes). The effect of the field with the mesh electrode on heat transfer coefficients in the nucleate boiling region is shown in Fig. 6(b). The boiling curves obtained by Zaghdoudi and Lallemand [24] for a mesh electrode at 0,10, 15 and $25 \mathrm{kV}$ are also shown in Fig. 5(c). They are displaced to lower superheats and the enhancing effect of the electric field at heat fluxes below 200 $\mathrm{kW} / \mathrm{m}^{2}$ is much greater, Fig. 6(c). The critical heat fluxes for the three sets of data, expressed as enhancement ratios, are shown in Fig.7. When compared at the same electrode potential, Fig. 7(a), the CHF enhancement ratios for the two mesh electrodes and the rod electrode are not greatly different, except for the rod electrode at $25 \mathrm{kV}$. When compared at the same nominal electric field strength, which is the basis indicated by theoretical models, the CHF enhancement is much greater in [24]. The data for the present study are in approximate agreement with the models of Johnson [34] and Berghmans [35] but the data from [24] require a large adjusting factor, as discussed in Section 1.3.

The shape of the boiling curve for the rod electrodes at $25 \mathrm{kV}$ in the heat flux range above $350 \mathrm{~kW} / \mathrm{m}^{2}$ and the high CHF stand out from all the other data but the measurements were reproducible, as shown earlier in Fig. 4.

\subsection{Discussion}

The differences between the conditions for the three data sets, two from this study, one from [24], are surface finish, electrode design and distance from the surface and, just possibly but not checkable, differences in the electrical conductivity of R123 due to impurities. 
For the same smooth surface finish, there is small improvement due to the less uniform field produced by the rod electrodes compared to the mesh electrode at heat fluxes below $350 \mathrm{~kW} / \mathrm{m}^{2}$. There is a slight reduction in wall superheat and a small improvement in CHF. Above this point, which might also be defined by the vapour volumetric production rate or the high wall superheat of $27 \mathrm{~K}$, the rod electrodes produce significantly better performance in respect of heat transfer coefficient and CHF. The increase in the slope of both boiling curves might be caused by a high density on the smooth surface of nucleation sites with small effective radii that are potentially active at this superheat. The greater effect for the rod electrodes may depend on the enhancement of nucleation by an electric field interacting with the factors that influence the field strength at the wall. As discussed in $[29,30]$ and section 1.3, the field strength at the wall depends on the distribution of bubbles on the wall and in the bulk liquid, as well as the electrode geometry. The assembly of rod electrodes should offer less resistance to the passage of bubbles than the mesh electrode.

The displacement of the boiling curves of [24] to low wall superheats is consistent with a high density of nucleation sites of larger effective radius on the rougher surface. The absence of a sudden positive change in slope at heat fluxes up to $550 \mathrm{~kW} / \mathrm{m}^{2}$ at $25 \mathrm{kV}$ in their experiments suggests that the phenomenon in the current experiments is associated with wall superheat and the distribution of nucleation site sizes, rather than the volumetric flux of vapour. A given potential applied to a mesh electrode twice the distance from the wall in [24] produces much higher enhancement of nucleate boiling, compared to the present study, Fig. 6, supporting the suggestion $[29,30]$ that the nominal field strength is a poor measure of its effectiveness. This is also apparent in the plots of enhancement of CHF, Fig. 7. Hydrodynamic models for CHF based on the nominal field strength are not quantitatively reliable but the data are in approximate agreement with their predicted trend.

The above speculative discussion shows that the experiments have raised questions, rather than answered them. The present data are in approximate agreement with the hydrodynamic models for CHF in the presence of an electric field but the models are unable to explain the differences from data for similar conditions from other sources. The issue of distortion of the electric field by electrode geometry and the distribution of bubbles is clearly important. There is a background question of the importance of free charges and charge relaxation time, and their sensitivity to the purity of R123. Good reproducibility was achieved in these experiments but the low, absolute value of the electrical conductivity was not measured. It is desirable to have a facility for accurate in situ measurement in future experiments. In addition, further experiments are required with fluids that have different values of the charge relaxation time.

It is not possible at this stage to assess the alternative contact line stability model for CHF on the basis of these experiments. It is necessary to turn to numerical modelling for guidance. 


\section{Theoretical model for growth of an axially-symmetrical bubble}

\subsection{Overview}

The model follows the general strategy of Son et al. [13] for matching a micro- model for the contact zone at the base of the bubble to a level-set macro-model for the liquid-vapour-solid regions, Figs. 8, 9. The new feature is the inclusion of forces due to the electric field. The models contain approximations. Some are similar to those in [13], some are introduced as a temporary measure to ease problems of numerical stability during the iterations required to match the models. The principal features of the models are summarised here for convenience.

Micro-model

- Smooth, perfectly wetted wall with zero contact angle between the liquid layer and an adsorbed film.

- Stationary contact line, near-parallel laminar motion in the liquid film driven by the gradient of pressure difference across the interface due to curvature, disjoining pressure, vapour recoil and electrical stress.

- Steady conduction across the liquid film.

- Locally uniform wall temperature, no allowance for local temperature gradients. The superheat is set by the output from the macro-model for the temperature field in the wall.

- Locally uniform electric field, at present set equal to the nominal field strength.

- No change in surface tension due to the electrical field.

Macro-model

- Two dimensional temperature fields in liquid and wall, uniform temperature equal to the saturation temperature in the vapour.

- Two dimensional electrical fields in the liquid and vapour, with free charge generation.

- Finite electrical conductivity in the liquid, linearly dependent on temperature; temperature dependence of electrical permittivity neglected.

- For calculation of electrical conductivity as a function of position only, the transient temperature field in the liquid is replaced by a steady temperature boundary layer at the wall, following the method of Karayiannis and $\mathrm{Xu}[29,30]$. This is the most serious of the temporary approximations. 


\subsection{Micro region}

The micro region corresponds approximately to the conventional microlayer at the base of a bubble, in which the motion is nearly parallel to the wall so that the lubrication approximations may be used. It extends from the contact line to a radial distance well beyond the range in which the disjoining pressure is significant. The model is terminated where the thickness $\delta(r)$ reaches a value dependent on the scale $h$ of the numerical grid in the macro-model.

The equation of mass conservation in the microlayer is

$\frac{q}{h_{f g}}=-\frac{1}{r} \frac{\partial}{\partial r} \int_{0}^{\delta} \rho_{l} r u_{l} d y$

where $q$ is the conductive heat flux from the interface, defined as $q=\frac{k_{l}\left(T_{w}-T_{\text {int }}\right)}{\delta}$. According to the lubrication theory used by Stephan and Hammer [12] and Son et al. [13], with $p_{l}$ the pressure in the liquid, the momentum equation in the micro region is written as

$\frac{\partial p_{l}}{\partial r}=\mu_{l} \frac{\partial^{2} u_{l}}{\partial y^{2}}$

Heat conducted through the thin film must match the evaporation from the vapour-liquid interface. Integrating the thermodynamic equation for change in fugacity with liquid pressure and temperature, Wayner et al. [11],

$d \ln f_{l}=\frac{V_{l}}{\bar{R} T_{l}} d p_{l}+\frac{h_{f g}}{\bar{R} T_{l}^{2}} d T_{l}$

leads to the energy equation in the form

$\frac{k_{l}\left(T_{w}-T_{\mathrm{int}}\right)}{\delta}=h_{e v}\left[T_{\mathrm{int}}-T_{v}+\frac{\left(p_{l}-p_{v}\right) T_{v}}{\rho_{l} h_{f g}}\right]$

The evaporative heat transfer coefficient $h_{e v}$ is obtained from kinetic theory as

$h_{e v}=2\left(\frac{M}{2 \pi \bar{R} T_{v}}\right)^{\frac{1}{2}} \frac{\rho_{v} h_{f g}^{2}}{T_{v}}$,

where $T_{v}=T_{\text {sat }}\left(p_{v}\right)$.

In the absence of an electric field, the pressure balance at the vapour-liquid interface leads to

$p_{l}=p_{v}-\sigma \kappa-\frac{\bar{A}}{\delta^{3}}+\frac{q^{2}}{\rho_{v} h_{f g}^{2}}$

where $\kappa=\frac{1}{r} \frac{\partial}{\partial r}\left(r \frac{\partial \delta}{\partial r} / \sqrt{1+\left(\frac{\partial \delta}{\partial r}\right)^{2}}\right)$ is the curvature of the interface, 
$\bar{A}$ is the Hamaker constant included in the disjoining pressure term, which for the R123-Copper substrate combination is calculated from the Lifshitz theory, Israelachvili [46], and can be found in Table 3. The last term on the right-hand side is the vapour recoil pressure. According to Gorla et al. [47], when an electrostatic field is applied in direction perpendicular to the heated wall another term is added to the right hand side of equation (14)

$$
p_{l}=p_{v}-\sigma \kappa-\frac{\bar{A}}{\delta^{3}}+\frac{q^{2}}{\rho_{v} h_{f g}^{2}}-\frac{\varepsilon_{0} E^{2} \varepsilon_{l}}{8 \pi}\left(\frac{\varepsilon_{l}}{\varepsilon_{v}}-1\right)\left(1+\left(\frac{\partial \delta}{\partial r}\right)^{2}\right)
$$

where $E$ is the electric field strength and $\varepsilon_{0}, \varepsilon_{l}, \varepsilon_{v}$ are the electric permittivities of vacuum, liquid, vapour respectively. The combination of the equations above, Son et al. [13], yields a system of three nonlinear first order ordinary differential equations (17-19), which, together with appropriate boundary conditions, may be solved in order to get the profile of the thin film, the evaporative heat flux and the temperature profile along the interface.

$\frac{\partial^{2} \delta}{\partial r^{2}}=\frac{\frac{\partial \delta}{\partial r}\left(1+\left(\frac{\partial \delta}{\partial r}\right)^{2}\right)}{r}+\frac{\left(1+\left(\frac{\partial \delta}{\partial r}\right)^{2}\right)^{\frac{3}{2}}}{\sigma}\left[\frac{\rho_{l} h_{f g}}{T_{v}}\left[T_{\mathrm{int}}-T_{v}-\frac{q}{h_{e v}}\right]-\frac{\bar{A}}{\delta^{3}}+\frac{q^{2}}{\rho_{v} h_{f g}^{2}}-\frac{\varepsilon_{0} E^{2} \varepsilon_{l}}{8 \pi}\left(\frac{\varepsilon_{l}}{\varepsilon_{v}}-1\right)\left(1+\left(\frac{\partial \delta}{\partial r}\right)^{2}\right)\right]$

$\frac{\partial T_{\mathrm{int}}}{\partial r}=-\frac{q \frac{\partial \delta}{\partial r}}{k_{l}+h_{e v} \delta}+\frac{3 T_{v} h_{e v} \mu \Gamma}{\left(k_{l}+h_{e v} \delta\right) \rho_{l}{ }^{2} h_{f g} r \delta^{2}}$

$\frac{\partial \Gamma}{\partial r}=-\frac{r q}{h_{f g}}$

where $\Gamma=\frac{-r \delta^{3} \rho_{l}}{3 \mu_{l}} \frac{\partial p_{l}}{\partial r}$ is the mass flow rate in the thin film

The boundary conditions for (17-19) are as follows: $\delta\left(R_{0}\right)=\delta_{0}, \frac{\partial \delta}{\partial r}\left(R_{0}\right)=0, T_{\mathrm{int}}\left(R_{0}\right)=T_{w}, \Gamma\left(R_{0}\right)=0$

where $R_{0}$ is the radius of the "dry-spot" beneath the bubble and the thickness of the equilibrium adsorbed film $\delta_{0}$ is given by $\delta_{0}=\left(\frac{\bar{A} T_{v} V_{l}}{M h_{f g}\left(T_{w}-T_{v}\right)}\right)^{\frac{1}{3}}$ (Wayner et al. [11])

\subsection{Macro region}

The macro region consists of the vapour bubble, the liquid around it and the wall. The model describes a vapour bubble nucleating on a superheated copper wall. Initially the bubble has the shape of a truncated sphere with a defined contact angle, Fig. 9. The model couples the momentum and continuity equations inside and outside the bubble. The temperature field is modelled only in the liquid and the wall outside the 
bubble, so at the interface and inside the bubble the temperature is uniform at the saturation temperature. The bubble interface is assumed to have a finite thickness represented by $\phi$-level set function, which is defined as a positive or negative distance from the interface, and an associated Heaviside function $H$ that has value zero in the bulk phases. The negative sign for $\phi$ is chosen for the vapour phase and the positive for the liquid phase. For the momentum equation for the vapour-interface-liquid region a "one-fluid" formulation has been used:

$$
\begin{aligned}
& \rho\left(\frac{\partial \mathbf{u}}{\partial t}+\mathbf{u} \cdot \nabla \mathbf{u}\right)=-\nabla p+\nabla \cdot \mu \nabla \mathbf{u}+\nabla \cdot \mu \nabla \mathbf{u}^{T}+\rho \mathbf{g}-\rho \beta_{T}\left(T-T_{s a t}\right) \mathbf{g}-\sigma \kappa \nabla H+\mathbf{F}_{E} \\
& \kappa(\phi)=\nabla \cdot\left(\frac{\nabla \phi}{|\nabla \phi|}\right) \text { is the curvature at the interface } \\
& \rho=\rho_{v}+\left(\rho_{l}-\rho_{v}\right) H, \mu=\mu_{v}+\left(\mu_{l}-\mu_{v}\right) H
\end{aligned}
$$

where $H$ the Heaviside function is

$$
H=\left\{\begin{array}{cc}
1 & \phi \geq 1.5 h \\
0 & \phi \leq-1.5 h \\
0.5+\phi / 3 h+\sin (2 \pi \phi / 3 h) /(2 \pi) & |\phi| \leq 1.5 h
\end{array}\right.
$$

The level set function $\phi$ advances as $\frac{\partial \phi}{\partial t}+\mathbf{u}_{\mathrm{int}} \cdot \nabla \phi=0$

and has to be reinitialized at each time step as:

$$
\frac{\partial \phi}{\partial t}=\frac{\phi_{0}}{\sqrt{\phi_{0}^{2}+h^{2}}}(1-|\nabla \phi|)
$$

where $\phi_{0}$ is the steady state solution of (27). The last term in (23) is the electric body force in (1), already discussed in section 1.3,

$$
\mathbf{F}_{E}=\rho_{e} \mathbf{E}-\frac{1}{2} E^{2} \nabla \varepsilon+\frac{1}{2} \nabla\left(E^{2} \rho \frac{\partial \varepsilon}{\partial \rho}\right)
$$

By neglecting small spatial variation of electric permittivity, time derivatives and the convection of free charges, the system of Poisson's equation for the electric potential (2) and the conservation of electric charge (3) can be rearranged as described in Sefiane et al. [48] to give a simplified equation for the free electric charge distribution :

$$
\rho_{e}=\frac{\varepsilon}{\sigma_{\mathrm{e}}} \nabla \Phi \cdot \nabla \sigma_{\mathrm{e}}
$$

where $\Phi$ is the electric potential, $\varepsilon=\varepsilon_{v}+\left(\varepsilon_{l}-\varepsilon_{v}\right) H$ is the electric permittivity defined in terms of the level 
set function properties and the electric conductivity changing with the temperature is $\sigma_{\mathrm{e}}=\sigma_{\mathrm{e}, \mathrm{sat}}\left(1+\alpha_{K}\left(T-T_{\text {sat }}\right)\right)$, where $\sigma_{\mathrm{e}, \mathrm{sat}}$ is the electric conductivity at saturation temperature and $\alpha_{K}$ is a coefficient which has been obtained experimentally by $\mathrm{Xu}$ [27] for R123 refrigerant, Table 3. Following the approximate method of Karayiannis and $\mathrm{Xu}$ [29,30], the temperature distribution in a thermal boundary layer of thickness $\delta_{T}$ is represented by a cubic equation and the distribution of free charge is given by

$$
\rho_{e}=\frac{\frac{3}{2} \frac{\varepsilon}{\delta_{T}}\left(1-\left(\frac{y}{\delta_{T}}\right)^{2}\right) \frac{\partial \Phi}{\partial y}}{1-\frac{3}{2} \frac{y}{\delta_{T}}+\frac{1}{2}\left(\frac{y}{\delta_{T}}\right)^{3}+\frac{1}{\alpha_{K}\left(T_{w}-T_{s a t}\right)}}
$$

The second and the third terms in (1) are derived from the properties of the level set function and the Clausius - Mossotti relationship (referred to in Karayiannis and $\mathrm{Xu}$ [29]) respectively to be

$$
\begin{aligned}
& -\frac{1}{2} E^{2} \nabla \varepsilon=-\frac{1}{2} E^{2}\left(\varepsilon_{l}-\varepsilon_{v}\right) \delta_{\varepsilon}(\phi) \nabla \varphi \\
& \frac{1}{2} \nabla\left(E^{2} \rho \frac{\partial \varepsilon}{\partial \rho}\right)=\frac{\varepsilon_{0}}{6} \nabla E^{2}\left(\frac{\varepsilon_{l}}{\varepsilon_{v}}-1\right)\left(\frac{\varepsilon_{l}}{\varepsilon_{v}}+2\right)
\end{aligned}
$$

The mass conservation equation including the effect of volume expansion due to liquid-vapour phase change is derived from the continuity equation and energy balance across the liquid -vapour interface, Son et al. [13]:

$$
\begin{aligned}
& \mathbf{m}=\rho\left(\mathbf{u}_{\text {int }}-\mathbf{u}\right)=\frac{\mathrm{k}_{l} \nabla \mathrm{T}}{\mathrm{h}_{\mathrm{fg}}} \\
& \nabla \cdot \mathbf{u}=-\frac{1}{\rho}\left(\frac{\partial \rho}{\partial t}+\mathbf{u} \cdot \nabla \rho\right)=\frac{\mathbf{m} \cdot \nabla \rho}{\rho^{2}}
\end{aligned}
$$

where $\mathbf{m}$ is the mass flux of the liquid evaporating at the interface. The vapour produced as a result of evaporation from the microlayer underneath the bubble is added to the vapour volume through a small number of computation cells adjacent to the heated wall. The evaporation is integrated and expressed as

$$
\begin{aligned}
& \left(\frac{1}{V_{c}} \frac{d V}{d t}\right)_{m i c}=\frac{\dot{m}_{m i c}}{V_{c} \rho_{v}} \delta_{\varepsilon}(\phi) \\
& \dot{m}_{m i c}=\int_{R_{0}}^{R_{1}} \frac{k_{l}\left(T_{w}-T_{\mathrm{int}}\right)}{h_{f g} \delta} r d r
\end{aligned}
$$


is the evaporation rate from the microlayer, $V_{c}$ is the volume of the control volume of size $3 h \times h$, where $h$ is the computational grid size and

$$
\delta_{\varepsilon}(\phi)=\frac{\partial H}{\partial \phi}
$$

is a smoothed delta function. The temperature field distribution equations in the liquid-vapour domain are

$$
\begin{array}{ll}
\rho c_{P}\left(\frac{\partial T}{\partial t}+\mathbf{u} . \nabla T\right)=\nabla . k \nabla T+\sigma_{e} \mathbf{E}^{2} & \text { for } \phi>0 \\
T=T_{\text {sat }}\left(p_{v}\right) & \text { for } \phi \leq 0 \\
k=k_{l} H^{-1} &
\end{array}
$$

The temperature field in the wall is governed by

$$
\rho_{w} c_{p_{w}} \frac{\partial T}{\partial t}=\nabla \cdot k_{w} \nabla T
$$

The term added to the right-hand side of (38) represents Joule heating in the liquid and can be neglected in the case of R123, Allen and Karayiannis [17]. The boundary and initial conditions are described below, see Fig. 9,

$$
\begin{array}{ll}
u=v=0, q_{l}=q_{w}, \frac{\partial \phi}{\partial y}=-\cos \varphi, \Phi=0 & \text { at } y=0 \\
\frac{\partial u}{\partial y}=\frac{\partial v}{\partial y}=\frac{\partial \phi}{\partial y}=0, T=T_{\text {sat }}, \Phi=\Phi_{0} & \text { at } y=Y \\
u=\frac{\partial v}{\partial r}=\frac{\partial T}{\partial r}=\frac{\partial \phi}{\partial r}=\frac{\partial \Phi}{\partial r}=0 & \text { at } r=0, R \\
q_{w}=q_{\mathrm{int}} & \text { at } y=-\frac{Y}{3}
\end{array}
$$

$\varphi$ is the apparent contact angle (Fig.9), for which an initial value is chosen based on experimental observations. $q_{w}, q_{l}$ are the heat fluxes at wall-liquid boundary and $q_{\text {int }}$ is a constant heat flux applied at the bottom of the wall. The value of the apparent contact angle changes with time due to the matching of the solutions in the micro and macro region. The other boundary conditions refer to the axisymmetry of the problem. Initial conditions are

$$
u(t=0)=0, T(t=0)=T_{\text {sat }}, \phi(t=0)=\psi(r, y), v(t=0)=0, \Phi(t=0)=0
$$

where $\psi$ is the initial shape of the bubble, usually chosen to be a truncated sphere with a defined radius. 


\subsection{Coupling between micro and macro models}

The matching of the solutions from the micro and macro region with a smooth interfacial profile is achieved by the following iterative procedure:

- $\quad$ for known Hamaker constant, the apparent contact angle $\varphi$ between the regions is guessed ;

- $\quad$ the macro region system of equations is solved and the value of $R_{1}$, the radial position of the interline between micro and macro region $\left(y=\frac{h}{2}\right.$ ), is derived (Fig. 9);

- $\quad R_{0}$ is derived from $\tan \varphi=\frac{h}{2\left(R_{1}-R_{0}\right)}$ for the guessed value of the contact angle $\varphi$, Fig. 9, in which $R_{1}$ is already known, and $\frac{h}{2}$ is the computational mesh size chosen for a particular simulation ;

- $\quad$ the micro region system is solved with boundary conditions for $R_{0}$ and the thin film profile $\delta(r)$ is derived;

- $\quad$ if the boundary conditions $\frac{\partial^{2} \delta}{\partial r^{2}}\left(R_{1}\right)=0$ and $\delta\left(R_{1}\right)=\frac{h}{2}$ are not fulfilled, then another value is guessed for the contact angle and the first four steps are repeated.

The micro region model has been implemented and solved through MATLAB code. Some results for the local temperature profile, local evaporative heat flux and the thin film profile in an isolated microlayer have been presented by Hristov et al. [49] in a conference paper. It was shown that the vapour recoil pressure and the electric field affect the profile of the bubble interface much more than the local evaporative heat flux in the microlayer. This emphasises the importance of the smooth matching of the micro and macro region models. The macro region model without a microlayer has been implemented through COMSOL Multiphysics commercial software and results have been presented by Sefiane et al. [48] that show that the elongation of the bubble in the direction of the electric field is more pronounced as the electric field strength is increased.

For the complete model presented here, the COMSOL Multiphysics code has been converted to MATLAB code and adjusted to "communicate" in both directions with the microlayer model in order to be able to match smoothly the interface of the bubble from the micro and macro region.

\subsection{Results from simulation and the relation to CHF}

The model simulates the growth and detachment of a single vapour bubble. When fully developed, it will be used to test the hypothesis that CHF may be explained in terms of competition between spreading of a dryspot and bubble detachment. The results presented here are for a bubble growing in R123 at atmospheric pressure on a copper plate with an input heat flux at the bottom of the plate of $100 \mathrm{~kW} / \mathrm{m}^{2}$, well below the 
CHF. The wall superheat is calculated by the simulation and is nearly uniform at $15 \mathrm{~K}$. Preliminary results are presented for conditions in the micro-region coupled to the macro-region, the growth and detachment of the bubble and the evolution of the radius $\mathrm{R}_{0}$ of the "dry-spot" (adsorbed layer) without an electric field and with a field of $5 \mathrm{MV} / \mathrm{m}$ (the maximum field used in the experimental study). The computational domain for the macro region is chosen to be $2 \mathrm{~mm} \times 4 \mathrm{~mm}$. The initial shape of the bubble in the macro model is a truncated sphere with contact angle $31^{\circ}$ (based on experimental observations) and contact radius $\mathrm{R}_{0}=0.0533$ $\mathrm{mm}$. $\mathrm{R}_{0}$ changes with time and at each time step new conditions in the micro-region are matched to the macro shape of the bubble.

Typical conditions in the inner part of the micro-region after $1 \mathrm{~ms}$ of growth with and without an electric field are presented in Fig. 10, showing the film thickness (a), liquid-vapour interface temperature (b), local evaporative heat flux (c) and the heat flux integrated from the edge of the adsorbed layer (d). The film thickness (a) increases with distance from the contact line. The temperature profile (b) drops from the superheated wall temperature to a temperature within $1 \mathrm{~K}$ of the saturation temperature presumed for the vapour inside the bubble over a distance of about $1 \mu \mathrm{m}$. The evaporative heat flux (c) has a maximum value of $34 \mathrm{MW} / \mathrm{m}^{2}$ in the immediate vicinity of the contact line, then decreases. The electric field has only a small effect at distances within $10^{-7} \mathrm{~m}$ of the contact line. Beyond that, the film thickness is reduced by the electric field, with consequent increases in the temperature at the liquid-vapour interface and increases in heat transfer, (c), (d). The electric field reduces the apparent contact angle for matching to the macro-region and causes a modest increase in the evaporative input to the bubble.

The bubble shapes calculated by the macro-model matched to the micro-region up to the time of bubble departure are shown in Fig. 11 (a) without an electric field and in Fig. 11 (b) with the electric field. Initially the bubble grows rapidly and the apparent contact radius with the wall expands. Contraction of the base of the bubble starts between $3 \mathrm{~ms}$ and $4 \mathrm{~ms}$. The first indication of necking occurs at $3 \mathrm{~ms}$ and is more pronounced with the electric field. After that, the elongation of the bubble by the electric field becomes pronounced, as observed in some studies of bubble detachment from orifices discussed in Section 1.4, and detachment occurs earlier, consistent with the observations of increased bubble frequency [20].

The calculations of dry-spot radius without and with an electric field are shown in Figure 12. In both cases the radius reaches a maximum value at about $3.5 \mathrm{~ms}$ that is smaller than the apparent contact radius in Fig. 11. The dry-spot is smaller and is rewetted more than $1 \mathrm{~ms}$ earlier with the electric field. The development of necking slightly before the reversal of the direction of motion of the contact line indicates that accurate modelling by the macro-model of the rapid changes in curvature as the stability develops are likely to be crucial to accurate modelling of bubble departure. The modelling was influenced by grid refinement, at 
present limited to reduce computation times, so it is likely that further grid refinement, combined with more accurate modelling of the temperature and electric fields close to the wall, will be required.

The CHF model depends on the interaction between dry-spot survival and the thermal response of the wall. At present, variations in wall temperature are calculated only in the macroscopic model. The wall temperature in the microscopic model at scales less than the computational grid is assumed to be uniform and the velocity of the contact line is neglected. For this particular example of growth on a copper wall at a nominal superheat of $15 \mathrm{~K}$, the depression of the wall surface temperature at the perimeter of the bubble is less than $0.5 \mathrm{~K}$ and the contact line velocity is $10 \mathrm{~mm} / \mathrm{s}$ at $1 \mathrm{~ms}$, Fig. 12. From Fig.10 (d), the integrated evaporative flux in the micro-region is $\sim 10 \mathrm{~W} / \mathrm{m}$, concentrated mainly in a zone of width $\sim 2 \times 10^{-7} \mathrm{~m}$. The local depression in temperature may be estimated from steady conduction in cylindrical coordinates,

$$
\Delta T=\frac{Q}{2 \pi k_{w}} \ln \frac{h}{r_{c}}
$$

where $r_{c}$ is the zone half-width and $h$ is the computational grid size in the macro-model, $10^{-4} \mathrm{~m}$. For this example, $\Delta T \sim 0.03 \mathrm{~K}$ and the isothermal wall approximation in the micro model is therefore appropriate. From the macro model, the maximum wall temperature rise at the centre of the dry-spot is only $0.25 \mathrm{~K}$ with or without the electric field. This would be considerably increased at the higher heat fluxes and wall superheats at the approach to $\mathrm{CHF}$, particularly on wall materials of much lower thermal conductivity than copper. The conditions near CHF may also increase the effect of the vapour recoil on the profile of the microlayer.

In this example the dry-spot shrinks back to the original size of the bubble, so that a stable bubble cycle can occur. The example has demonstrated that the methodology is now in place to investigate the motion of contact lines in the presence of electric fields and the development of hot-spots under bubbles either in a single bubble cycle or escalating over several cycles.

By extending the macro model to fully 3-dimensional simulations, it will be possible to investigate the effect of distortion of the electric field near the wall by detached bubbles.

\section{CONCLUSION}

Nucleate boiling heat transfer coefficients and CHF for saturated boiling of R123 on a polished copper wall at atmospheric pressure were enhanced by a dc electric field. The data for two designs of electrode (parallel rods creating a non-uniform field and a mesh creating a more uniform field but creating more obstruction to bubbles) were similar for fields up to $4 \mathrm{MV} / \mathrm{m}$. At the highest field strength of $5 \mathrm{MV} / \mathrm{m}$, there was a large 
nonlinear increase in heat transfer coefficient for the rod electrodes at high heat flux, high superheat, which may have been caused by the greater density of very small nucleation sites on the smooth surface. There was also a large increase in CHF.

There were significant differences between the data from this study and those from a study by Zaghdoudi and Lallemand [24] on a copper wall with a rougher surface and with a similar mesh electrode at a greater distance from the wall $(10 \mathrm{~mm}$ instead of $5 \mathrm{~mm})$. As expected, the nucleate boiling curves in [24] had lower wall superheats without and with an electric field. The critical heat fluxes were comparable when plotted against electrode voltage (except for the rod electrode at $25 \mathrm{kV}$ ) but not when plotted in the theoretically appropriate manner against electric field strength. Extended hydrodynamic models for the enhancement of CHF were not successful in reconciling the data from the two studies.

The issues identified for further investigation were

- the effect of detached bubbles on the distortion of the electric field at the heated wall by detached bubbles, possibly related to details of electrode geometry;

- the effect of free charge generation and possible variations in the electrical conductivity of refrigerants due to impurities;

- the influence of wall surface and bulk properties.

Progress has been made in developing a model based on the growth of individual bubbles. A numerical simulation of bubble growth involving matching of models for the macro and micro regions in the presence of an electric field has been developed that can be used to investigate the increase in wall temperature due to dry-spots. Preliminary solutions have been achieved for bubble detachment and the evolution of dry-spots with changes of wall temperature that may lead to CHF, with and without an electric field.

\section{Acknowledgement}

\section{Nomenclature}

$$
\begin{aligned}
& \bar{A} \text { - Hamaker constant, } J \\
& A \text { - empirical constant } \\
& B \text { - empirical constant } \\
& c_{P} \text { - specific heat at constant pressure, } J /(\mathrm{kg} \mathrm{K}) \\
& d \text { - characteristic length, } m
\end{aligned}
$$


$E$ - electric field strength, $V / m$

$E l$ - electric influence number

$E l^{\prime}$ - electric influence number

$E l^{*}$ - electric influence number

$f_{l}$ - fugacity

g - gravitational vector, $m / s^{2}$

$H$ - Heaviside step function

$h$ - grid spacing, $m$

$h_{0}$ - heat transfer coefficient without electric field

$h_{E}$ - heat transfer coefficient with electric field

$h_{e v}=2 \sqrt{\frac{M}{2 \pi \bar{R} T_{v}}} \frac{\rho_{v} h_{f g}^{2}}{T_{v}}$-evaporation heat transfer coefficient $W /\left(m^{2} K\right)$

$h_{f g}$-latent heat of evaporation, $J / k g$

$H V$ - applied high voltage, $k V$

$k$ - thermal conductivity, $W /(m K)$

$M$ - molecular weight, $\mathrm{kg} / \mathrm{mol}$

m - mass flux vector, $\mathrm{kg} /\left(\mathrm{m}^{2} \mathrm{~s}\right)$

$\dot{m}_{\text {mic }}$ - evaporation rate from the microlayer, $\mathrm{kg} / \mathrm{s}$

$\mathrm{Nu}$-Nusselt number

Pr - Prandtl number

$p$ - pressure, $N / m^{2}$

$\bar{p}$ - empirical constant

$Q$ - integrated heat flux, $W / m$

$q$ - heat flux, $W / m^{2}$

$q_{c r}(E)=q_{E}-$ critical heat flux with electric field, $k W / m^{2}$

$q_{c r}(0)=q_{0}$ - critical heat flux without electric field, $\mathrm{kW} / \mathrm{m}^{2}$

$r$ - radial coordinate, $m$

$r_{c}$ - half- width of zone in (48), $m$ 
$R$ - radius of computational domain, $m$

$\bar{R}$ - universal gas constant

$R_{o}$ - radius of dry region beneath a bubble, $m$

$R_{1}$ - radial location of the interface at $y=h / 2, m$

$t$ - time, $s$

$T$ - temperature, $K$

$\Delta T=T_{w}-T_{s a t}$ - wall superheat, $K$

$\mathbf{u}$-velocity vector $(u, v)$

$u$ - r-directional velocity, $\mathrm{m} / \mathrm{s}$

$v$ - y-directional velocity, $\mathrm{m} / \mathrm{s}$

$V$ - bubble volume, $\mathrm{m}^{3}$

$V_{c}$ - control volume, $\mathrm{m}^{3}$

$V_{l}$ - molar volume, $\mathrm{m}^{3} / \mathrm{mol}$

$y$ - vertical coordinate, $m$

$Y$ - height of computational domain, $m$

\section{Greek symbols}

$\alpha_{K}$ - coefficient of thermal increase of electric conductivity $\mathrm{R} 123,1 / K$

$\beta_{T}$ - coefficient of thermal expansion, $1 / K$

$\Gamma$ - mass flow rate in the microlayer, $\mathrm{kg} / \mathrm{s}$

$\delta$ - thickness, $m$

$\delta_{0}$ - initial thickness, $m$

$\delta_{\varepsilon}(\phi)$-delta function

$\delta_{T}$ - thermal boundary layer thickness, $m$

$\varepsilon$ - electric permittivity, $F / m$

$\varepsilon_{0}$ - electric permittivity vacuum, $F / m$ 
$\varepsilon_{r}$ - relative electric permittivity

$\kappa$ - interface curvature, $1 / m$

$\lambda_{d}$-wavelength, $m$

$\mu$ - dynamic viscosity, N.s $/ m^{2}$

$\rho$ - mass density, $\mathrm{kg} / \mathrm{m}^{3}$

$\rho_{e}$ - electric charge density, $C / \mathrm{m}^{3}$

$\sigma$ - surface tension, $\mathrm{N} / \mathrm{m}$

$\tau$-charge relaxation time, $s$

$\sigma_{\mathrm{e}}$ - electric conductivity, $S$

$\phi$ - level set function

$\Phi$ - electric potential, $V$

$\varphi$ - apparent contact angle, deg

$\psi$-initial bubble shape profile

\section{Subscripts}

int -interface

$l$ - liquid

sat - saturation

$v$ - vapour

$w$-wall interface

\section{References}

[1] N. Zuber, On the stability of boiling heat transfer, Trans. ASME, J. Heat Transfer, vol. 90, pp. 711-720, 1958.

[2] Y. Haramura and Y. Katto, A new hydrodynamic model of critical heat flux, applicable widely to both pool and forced convection boiling on submerged bodies in saturated liquids, Int. J. Heat Mass Transfer, vol. 26, pp. 389-399 , 1983.

[3] S. Nishio, N. Gotoh, N. Nagai, Observation of boiling structures in high heat-flux boiling, Int. J. Heat Mass Transfer, vol. 41, pp. 3191-3201, 1998.

[4] H.J.Chung and H.C. No, Simultaneous visualization of dry spots and bubbles for pool boiling of R-113 on a horizontal heater, Int. J. Heat Mass Transfer, vol. 46, pp. 2239-2251, 2003.

[5] T.G, Theofanous, J.P. Tu, A.T. Dinh and T.N. Dinh, ,. The boiling crisis phenomenon Part I: nucleation and nucleate boiling heat transfer, Experimental Thermal and Fluid Science, vol. 26, pp. 755-792, 2002.

[6] T.G, Theofanous, T.N. Dinh, J.P.Tu and A.T. Dinh, The boiling crisis phenomenon Part II: dryout dynamics and burnout, Experimental Thermal and Fluid Science, vol. 26, pp. 793-810, 2002. 
K. Sefiane, D. Benielli and A. Steinchen, A new mechanism for pool boiling crisis, recoil instability and contact angle influence, Colloids and Surfaces A: Physicochemical and Engineering Aspects, vol. 142, pp. 361- 373, 1998.

[8] K. Sefiane, A new approach in the modeling of the critical heat flux and enhancement techniques, AIChE Journal, vol. 47, pp. 2402-2412, 2001.

[9] V.S. Nikolayev and D.A. Beysens, Boiling crisis and non-equilibrium drying transition, Europhysics Letters, vol. 47, pp. 345-351, 1999.

[10] V.S. Nikolayev, D. Chatain and D. Beysens, Is CHF triggered by the vapor recoil effect?, 2006 ECI Conf. on Boiling Heat Transfer, Spoleto, Paper 136, 2006. UPDATE REFERENCE TO PAPER IN SPECIAL ISSUE

[11] P. C. Wayner, Jr., Y. K. Kao and L. V. Lacroix, The interline heat transfer coefficient of an evaporating wetting film, Int. J. Heat Mass Transfer, vol. 19, pp. 487-492, 1976.

[12] P. Stephan and J. Hammer, A new model for nucleate boiling heat transfer, Heat and Mass Transfer, vol. 30, pp. 119-125, 1994.

[13] G. Son, V.K. Dhir, N. Ramanujapu, Dynamics and heat transfer associated with a single bubble during nucleate boiling on a horizontal surface, Trans. ASME, J. Heat Transfer, vol. 121, pp. 623-631, 1999.

[14] A. Mukherjee and V.K. Dhir, Study of lateral merger of vapor bubbles during nucleate pool boiling, Trans. ASME, J. Heat Transfer, vol. 126, pp. 1023-1039, 2004.

[15] B. Mathieu, O. Lebaigue and L. Tadrist, Numerical investigation of a dynamic contact line model for perfectly wetting liquids on a heated wall of finite conductivity, Proc. 12th Int. Heat Transfer Conf. Grenoble, vol.3, pp. 455-460, 2002.

[16] B. Mathieu, O. Lebaigue and L. Tadrist, Influence of a dynamic contact line model on the characteristics of nucleate wall boiling computed with a DNS approach, Proc. 5th Int. Conf. on Multiphase Flow, Yokohama, Paper 439.

[17] P.H.G. Allen and T. G. Karayiannis, Electrohydro-dynamic enhancement of heat transfer and fluid flow-Review paper, Heat Recovery Systems \& CHP, vol. 15, No. 5, pp. 389-423, 1995.

[18] P. Di Marco and W. Grassi, Effect of force fields on pool boiling flow patterns, 2006 ECI Conf. on Boiling Heat Transfer, Spoleto, Paper 136, 2006. UPDATE REFERENCE TO PAPER IN SPECIAL ISSUE

[19] M.M. Ohadi, N. Sharaf and D.A. Nelson, Electrohydrodynamic enhancement of heat transfer in a shell-and-tube heat exchanger, Experimental Heat Transfer, vol. 14, pp. 19 - 39, 1991.

[20] J. Ogata, and A. Yabe, Augmentation of boiling heat transfer by utilizing the EHD effect - EHD behaviour of boiling bubbles and heat transfer characteristics, Int. J. Heat Transfer Mass, Vol. 36, pp. 783 -791, 1993.

[21] M. Markels and R. L. Durfee, The effect of applied voltage on boiling heat transfer, AIChE J., vol. 10, pp. 106-110, 1964.

[22] L.D. Landau and E.M. Lifshitz, Electrodynamics of continuous media, Addison-Wesley, Reading, Masschussetts ,1960.

[23] M.C. Zaghdoudi and M. Lallemand, Study of the behaviour of a bubble in an electric field: steady shape and local fluid motion, Int. J. Thermal Sciences, vol. 39, pp.39-52, 2000.

[24] M.C. Zaghdoudi and M. Lallemand, Electric field effects on pool boiling, Journal of Enhanced Heat Transfer, vol. 9, pp. 187-208, 2002.

[25] S.-D. Oh and H.-Y. Kwak, A study of bubble behaviour and boiling heat transfer enhancement under electric field, Heat Transfer Engineering, vol. 21, pp. 33-45, 2000.

[26] 3M Product information sheet.

[27] Y. Xu, Effects of electric fields on pool boiling heat transfer, Ph. D. Thesis, South Bank University, UK 1995.

[28] T.G. Karayiannis, EHD boiling heat transfer enhancement of R123 and R11 on a tube bundle, Applied Thermal Engineering, vol. 18, pp. 809-817, 1998.

[29] T.G. Karayiannis, Y. Xu, Electric field effect in boiling heat transfer. Part A: Simulation of the electric field and electric forces, J. Enhanced Heat Transfer, vol. 5, pp. 217-229, 1998. 
T.G. Karayiannis and Y. Xu, Electric field effect in boiling heat transfer. Part B: Electrode geometry, J. Enhanced Heat Transfer, vol. 5, 231-247, 1998.

[31] M. Uemura, S. Nishio and I. Tanasawa, Enhancement of pool boiling heat transfer by static electric field, Proc. 9th Int. Heat Transfer Conference, Jerusalem, vol.4, pp. 75-80, 1990.

[32] G. Ahsmann and R. Kronig, The influence of electric fields on the convective heat transfer in liquids, Applied Scientific Research A, vol. 2, pp. 235-244, 1950.

[33] E. Bonjour, J. Verdier and L. Weil, Electro-convection effects on heat transfer, Chemical Engineering Progress, vol. 58, pp. 63-66, 1962.

[34] R. L. Johnson, Effect of an electric field on boiling heat transfer, AIAA J., vol. 6, pp. 1456 - 1460, 1968.

[35] J. Berghmans, Electrostatic fields and the maximum heat flux, Int. J. Heat Mass Trans., vol. 19, pp. 791- 797, 1976.

[36] R.F. Lovenguth and D. Hanesian, Boiling heat transfer in the presence of nonuniform, direct current electric fields, Ind. Eng. Chem. Fundamentals, vol. 10, pp. 570-576, 1971.

[37] E. Iacona, C. Herman, S. Chang and Z. Liu, Electric field effect on bubble detachment in reduced gravity environment, Experimental Thermal and Fluid Science, online doi:10.1016/j.expthermflusci.2006.03.029, 2006.

[38] Z. Liu, C. Herman, D. Mewes, Visualization of bubble detachment and coalescence under the influence of a nonuniform electric field, Experimental Thermal and Fluid Science, online doi:10.1016/j.expthermflusci.2006.03.025, 2006.

[39] C. Herman and E. Iacona, Modeling of bubble detachment in reduced gravity under the influence of electric fields and experimental verification, Heat and Mass Transfer, vol. 40, pp. 943-957, 2004.

[40] K.J. Cheng and J.B. Chaddock, Maximum size of bubbles during nucleate boiling in an electric field, Int. J. Heat Fluid Flow, vol. 7, pp. 278-282.

[41] R. Kumar and N.R. Kuloor, The formation of bubbles and drops, Advances in Chemical Engineering, Am. Chem. Soc., Washington, vol. 8, pp. 256-368.

[42] H.J. Cho, I.S. Chang, Y.C. Kweon and M.H. Kim, Study of the behaviour of a bubble attached to a wall in a uniform electric field, Int. J. Multiphase Flow, vol. 22, pp. 909-922, 1996.

[43] P. Di Marco, W. Grassi, G. Memoli, T. Takamasa, A. Tomiyama and S. Hosokawa, Influence of electric field on single gas-bubble growth and detachment in microgravity, Int. J. Multiphase Flow, vol. 29, pp. 559-578, 2003.

[44] H. Auracher and W. Marquardt, Heat transfer characteristics and mechanisms along entire boiling curves under steady state and transient conditions, Int. J. Heat and Fluid Flow, vol. 25, pp. 223-242, 2004.

[45] K. Yamashita and A. Yabe, Electrodynamic enhancement of falling film evaporation heat transfer and its long-term effect on heat exchangers, Trans. ASME, J. Heat Transfer, vol. 119, pp. 339-347, 1997.

[46] J. Israelachvili, Intermolecular forces, 2nd. ed., Academic Press, Washington, 1992.

[47] R. S. R. Gorla, J. E. Gatica, B. Ghorashi and P. Ineure, L. Byrd, Heat transfer in a thin liquid film in the presence of an electric field, Chem. Eng. Comm. 191, 718-731, 2004.

[48] K. Sefiane, Y. Hristov, D.B.R. Kenning, T.G. Karayiannis, D. Zhao, Modelling of the growth and detachment of a vapour bubble and the effect of an electric field in nucleate boiling regime, 13th International Heat Transfer Conference, 13-18 August, Sydney, 2006.

[49] Y. Hristov, D. Zhao, K. Sefiane, T.G. Karayiannis, D.B.R. Kenning, Critical heat flux (CHF) modelling in pool boiling heat transfer, including the effect of an electric field, Proceedings of 9 th UK National Conference of Heat Transfer, Manchester, 2005.

\begin{tabular}{|c|c|c|c|c|c|}
\hline fluid & $T_{\text {sat }}\left({ }^{\circ} \mathrm{C}\right)$ & $\varepsilon_{\mathrm{rl}}$ & $\sigma_{\mathrm{e}}\left(\Omega^{-1} \mathrm{~m}^{-1}\right)$ & $\tau(\mathrm{s})$ & ref. \\
\hline $\mathrm{R}-123$ & 28 & 3.42 & $3.4 \times 10^{-8}$ & $0.9 \times 10^{-3}$ & {$[23,24]$} \\
\hline
\end{tabular}




\begin{tabular}{|c|c|c|c|c|c|}
\hline R-113 & 47 & 2.40 & $1.1 \times 10^{-11}$ & 2.1 & {$[23]$} \\
& & & $7.7 \times 10^{-9}$ & $2.8 \times 10^{-3}$ & {$[24]$} \\
& & & $2.2 \times 10^{-11}$ & 1.0 & {$[25]$} \\
\hline n-pentane & 36 & 1.80 & $6.7 \times 10^{-9}$ & $2.4 \times 10^{-3}$ & {$[23]$} \\
& & & $4.7 \times 10^{-9}$ & $3.4 \times 10^{-3}$ & {$[24]$} \\
\hline R-11 & 24 & 2.28 & $1.6 \times 10^{-11}$ & 1.3 & {$[25]$} \\
\hline FC-72 & 56 & 1.75 & $1.0 \times 10^{-13}$ & 155 & {$[25,26]$} \\
\hline
\end{tabular}

Table 1 Electrical properties of liquids boiling at 1 bar pressure 


\begin{tabular}{|l|c|c|}
\hline \multicolumn{1}{|c|}{ Reference } & $B$ & $q_{c r}(E) / q_{c r}(0)$ \\
\hline Johnson [32] & $\frac{\varepsilon_{0} \varepsilon_{r l}\left(\varepsilon_{r l}-\varepsilon_{r v}\right)^{2}}{\varepsilon_{r v}\left(\varepsilon_{r l}+\varepsilon_{r v}\right)}$ & {$\left[E l^{*}+\left(E l^{* 2}+1\right)^{1 / 2}\right]^{1 / 2}$} \\
\hline Berghmans [33] & $\varepsilon_{0} \varepsilon_{r v}$ & {$\left[E l^{*}+\left(E l^{* 2}+1\right)^{1 / 2}\right]^{1 / 2}$} \\
\hline Lovenguth and Hanesian [34] & $\frac{\varepsilon_{0}\left(\varepsilon_{r l}-1\right)^{2}}{\left(\varepsilon_{r l}+1\right)}$ & {$\left[E l^{*}+1\right]^{1 / 2}$} \\
\hline
\end{tabular}

Table 2. Electrohydrodynamic models for CHF enhancement, based on [23].

\begin{tabular}{|c|c|c|c|c|c|c|c|}
\hline $\begin{array}{r}T_{\text {sat }} \\
(\mathrm{K})\end{array}$ & $\begin{array}{c}q_{\mathrm{int}} \\
\left(\mathrm{W} / \mathrm{m}^{2}\right)\end{array}$ & $\begin{array}{c}\sigma \\
(\mathrm{N} / \mathrm{m})\end{array}$ & $\begin{array}{c}\rho_{v} \\
\left(\mathrm{~kg} / \mathrm{m}^{3}\right)\end{array}$ & $\begin{array}{c}\rho_{l} \\
\left(\mathrm{~kg} / \mathrm{m}^{3}\right)\end{array}$ & $\begin{array}{c}\rho_{w} \\
\left(\mathrm{~kg} / \mathrm{m}^{3}\right)\end{array}$ & $\begin{array}{c}\mu_{v} \\
\left(\mathrm{~N} . \mathrm{s} / \mathrm{m}^{2}\right)\end{array}$ & $\begin{array}{c}\mu_{l} \\
\left(\mathrm{~N} . \mathrm{s} / \mathrm{m}^{2}\right)\end{array}$ \\
\hline 300.848 & $1.00 \mathrm{E}+05$ & 1.50E-02 & 6.49 & 1462.2 & 8700 & 1.17E-05 & 4.19E-04 \\
\hline $\begin{array}{c}\alpha_{K} \\
(1 / K)\end{array}$ & $\begin{array}{c}\beta_{T} \\
(1 / \mathrm{K})\end{array}$ & $\begin{array}{c}k_{l} \\
(\mathrm{~W} /(\mathrm{mK}))\end{array}$ & $\begin{array}{c}k_{w} \\
(\mathrm{~W} /(\mathrm{mK}))\end{array}$ & $\begin{array}{c}h_{f g} \\
(\mathrm{~J} / \mathrm{kg})\end{array}$ & $\begin{array}{c}c_{P l} \\
(\mathrm{~J} /(\mathrm{kg} \mathrm{K}))\end{array}$ & $\begin{array}{c}c_{P_{w}} \\
(\mathrm{~J} /(\mathrm{kg} \mathrm{K}))\end{array}$ & \\
\hline 0.0263 & $7.00 \mathrm{E}-04$ & 0.106 & 400 & $1.68 \mathrm{E}+05$ & 982 & 385 & \\
\hline $\begin{array}{c}\varepsilon_{l} \\
(\mathrm{~F} / \mathrm{m})\end{array}$ & $\begin{array}{c}\varepsilon_{v}=\varepsilon_{0} \\
(\mathrm{~F} / \mathrm{m})\end{array}$ & $\begin{array}{c}g \\
\left(\mathrm{~m} / \mathrm{s}^{2}\right)\end{array}$ & $\begin{array}{c}\sigma_{\text {e.sat }} \\
\left(\Omega^{-1} \mathrm{~m}^{-1}\right)\end{array}$ & $\begin{array}{l}\bar{A} \\
(\mathrm{~J})\end{array}$ & $\begin{array}{c}M \\
(\mathrm{~kg} / \mathrm{mol})\end{array}$ & $\begin{array}{c}\bar{R} \\
(\mathrm{~J} / \mathrm{Kmol}) \\
\end{array}$ & \\
\hline $4.134 \mathrm{E}-1$ & $8.85 \mathrm{E}-12$ & 9.81 & $3.40 \mathrm{E}-08$ & $2.446 \mathrm{E}-21$ & 0.152 & 8.314 & \\
\hline
\end{tabular}

Table 3. Properties of R-123 and copper wall used for the micro and macro region simulations. 


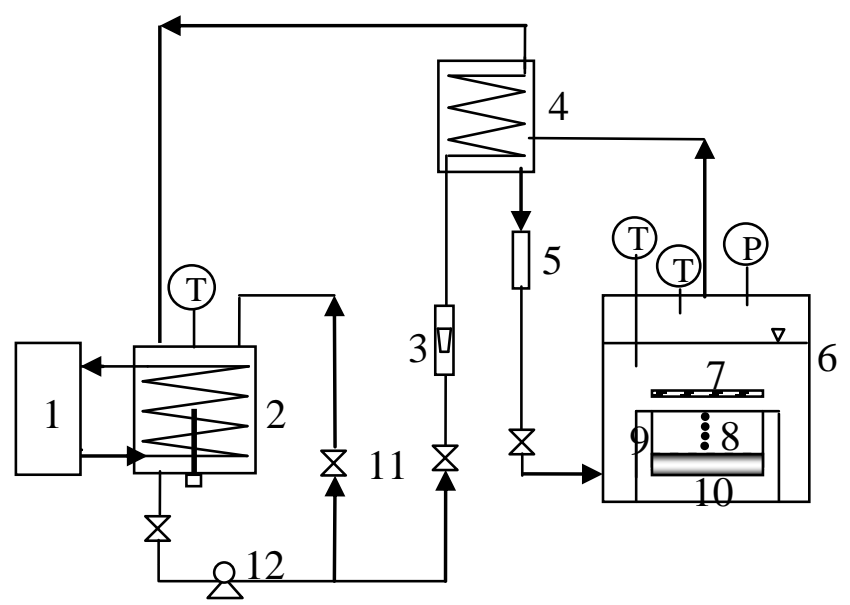

1. R134a cooling unit 2. Evaporator 3. Water flow meter

4. Condenser 5. Filter/dryer 6. Boiling chamber 7. Electrode 8. Thermocouples 9. Heating copper block, 10.

Heater 11. Valve 12. Pump

Fig. 1. Schematic of the experimental rig. 


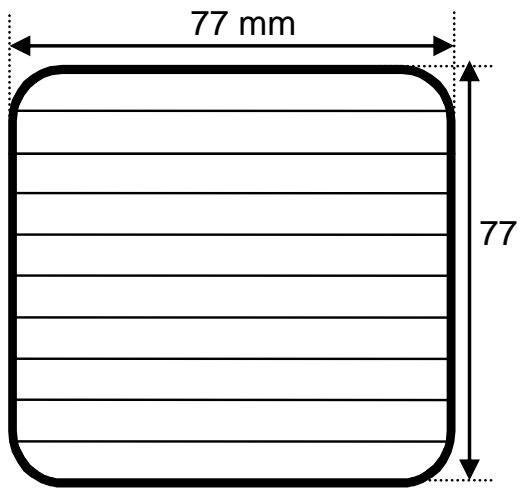

frame bar diameter $2.4 \mathrm{~mm}$ inside rod diameter $1.56 \mathrm{~mm}$

(a) rod electrodes

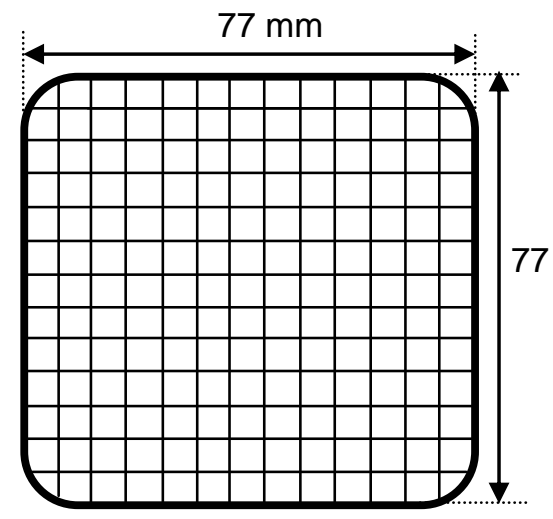

wire diameter $1.56 \mathrm{~mm}$

(b) mesh electrode

Fig. 2. Electrode geometries 


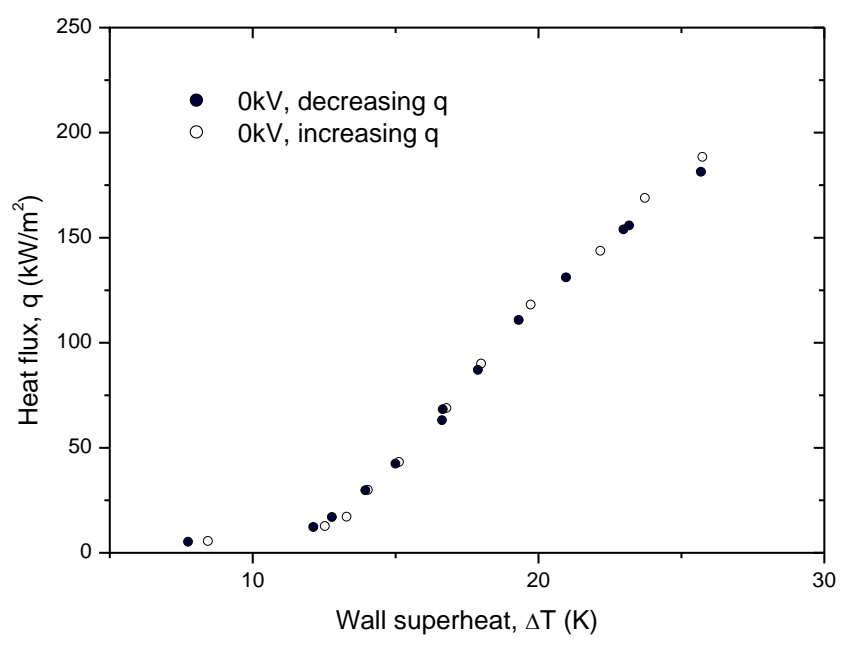

Fig. 3. Test for hysteresis, rod electrodes, $0 \mathrm{kV}$.

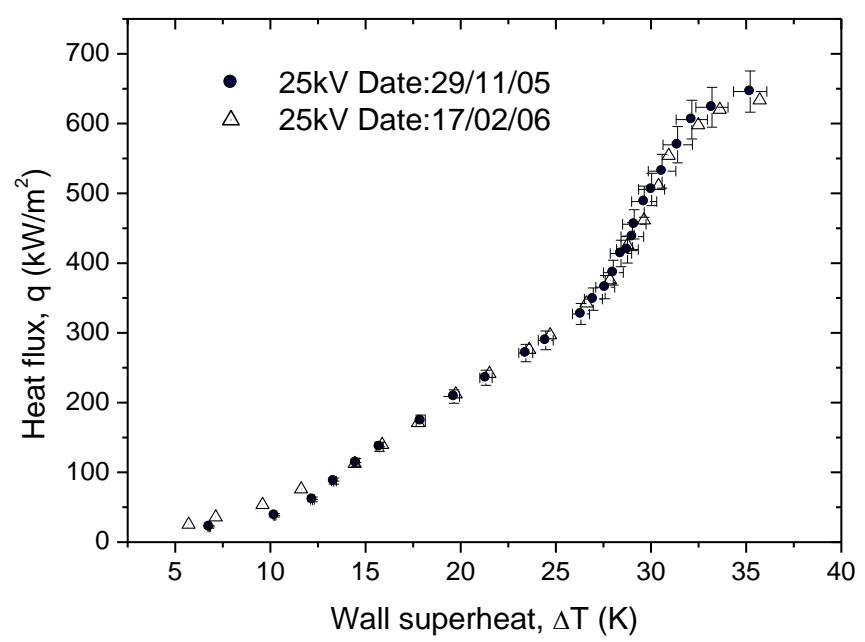

Fig. 4. Long-term reproducibility and experimental uncertainty, rod electrodes, $25 \mathrm{kV}$. 


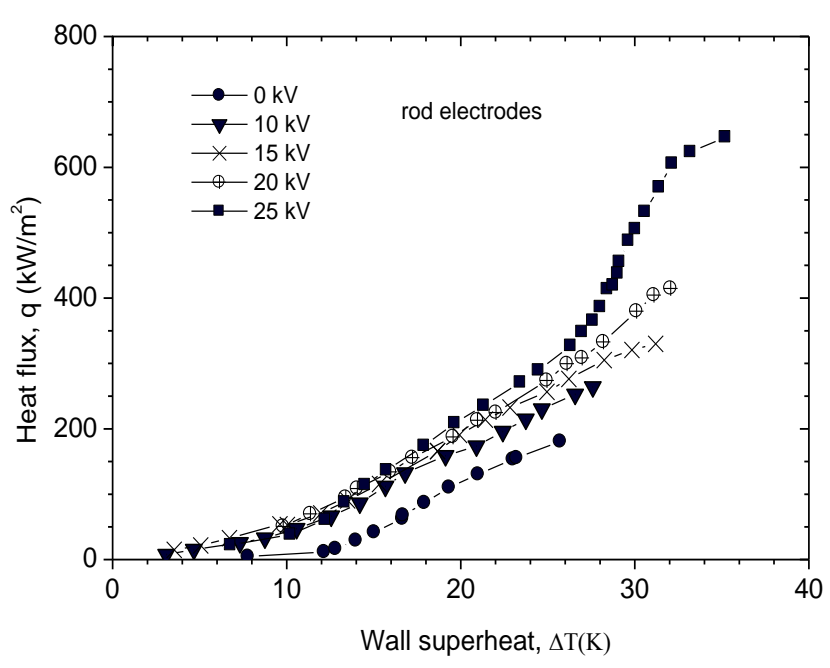

(a)

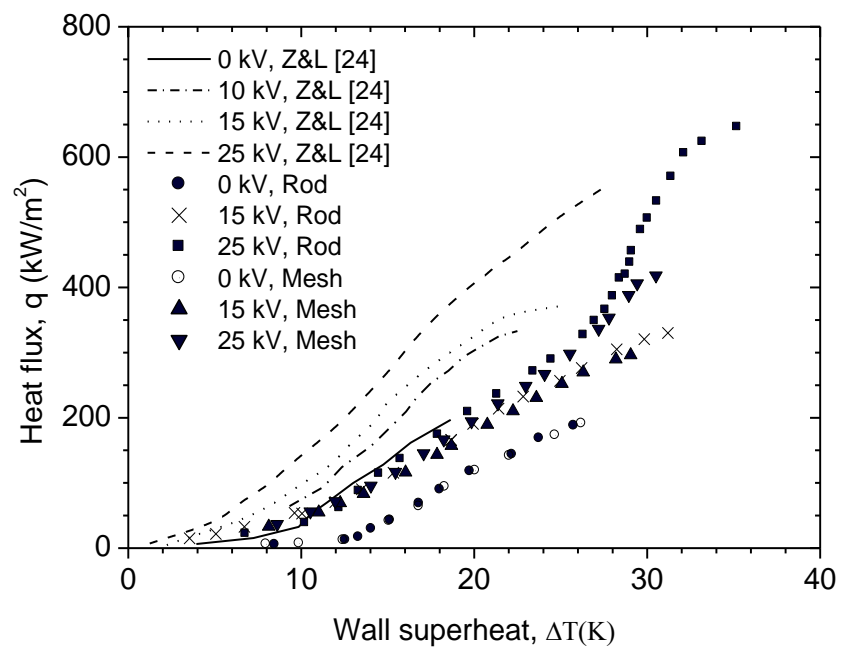

(c)

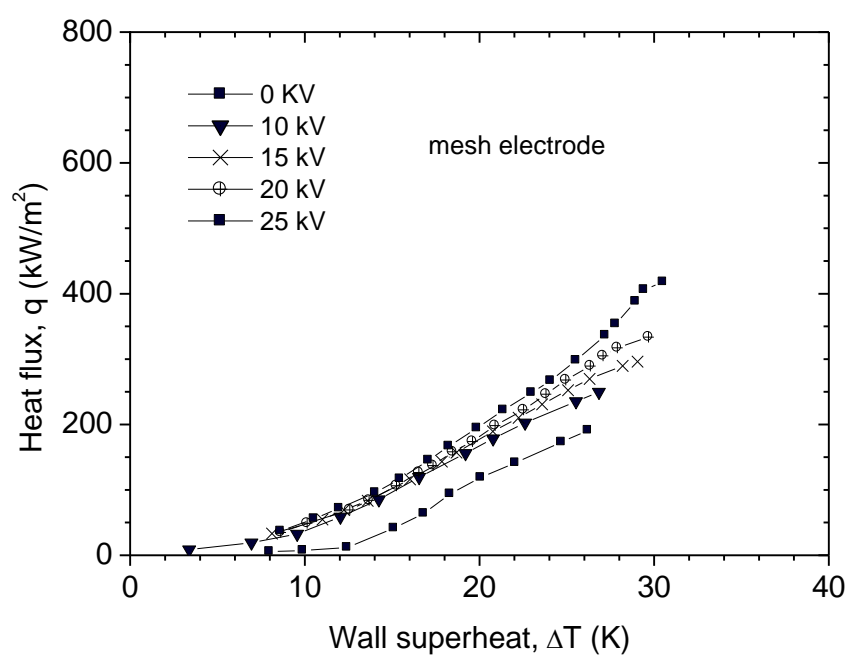

(b)

Fig. 5. Boiling curves for R123

(a) rod electrodes, (b) mesh electrode,

(c) comparison plus data for mesh electrode

from Zaghdoudi and Lallemand [24]. 


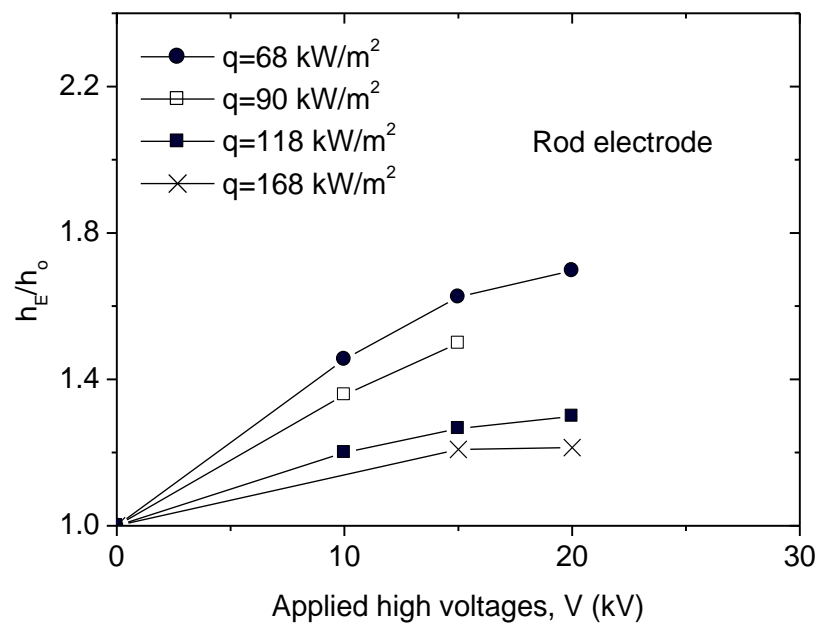

(a)

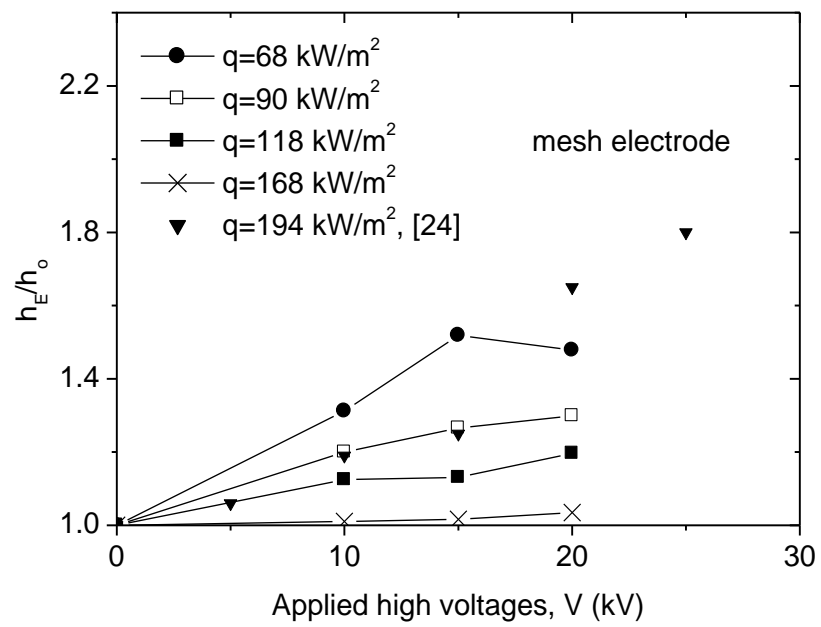

(b)

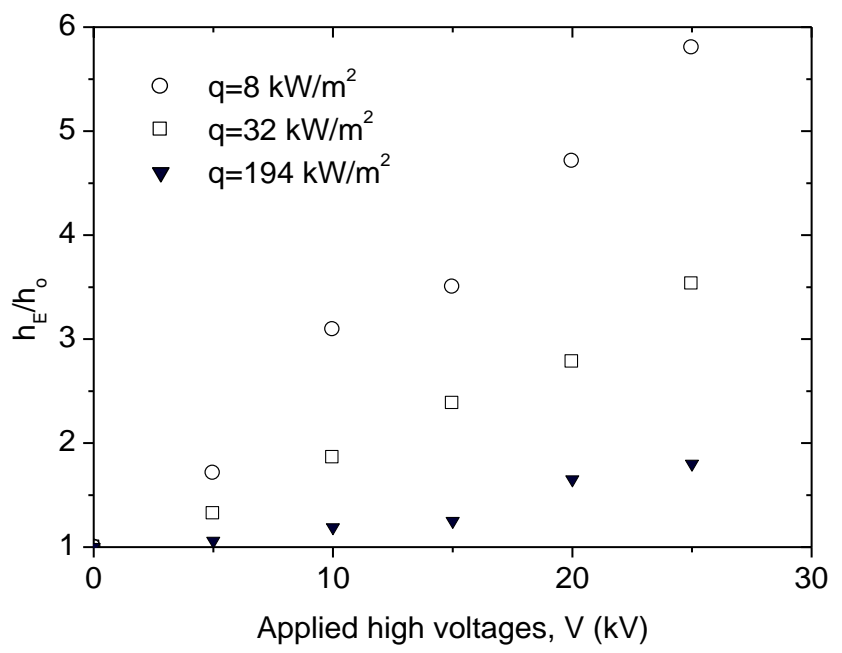

(c)

Fig. 6. Enhancement of nucleate boiling by electric field

(a) rod electrodes (b) mesh electrode, (c) mesh electrode, Zaghdoudi and Lallemand [24] 


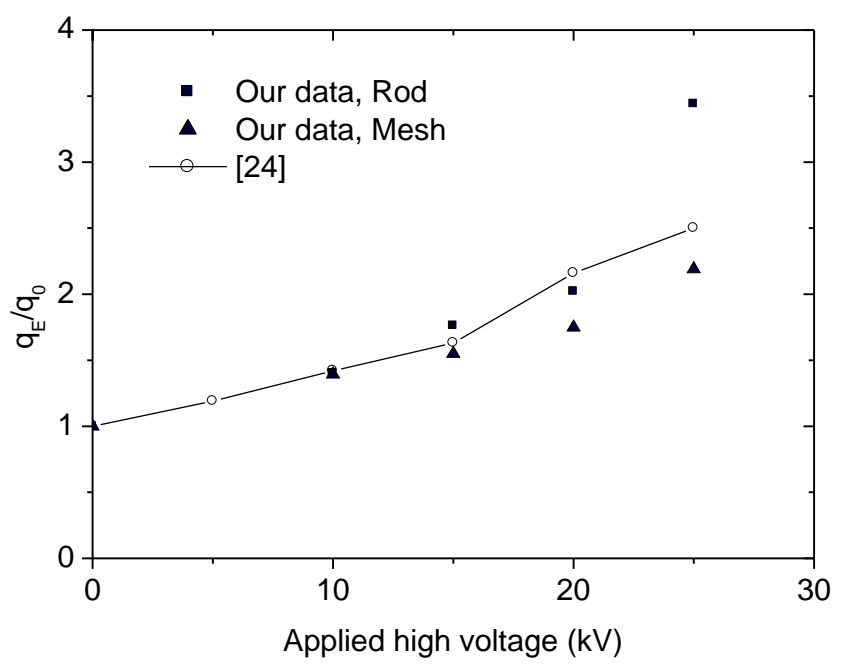

(a)

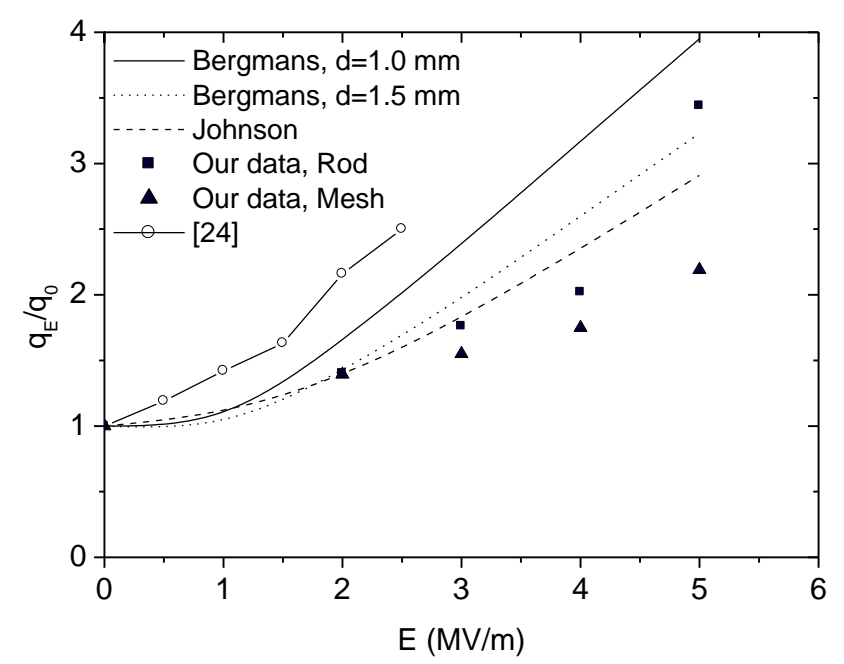

(b)

Fig. 7. Enhancement of CHF by electric field, rod electrodes, mesh electrodes and data of [24], plotted against (a) electrode voltage, (b) electric field strength. 


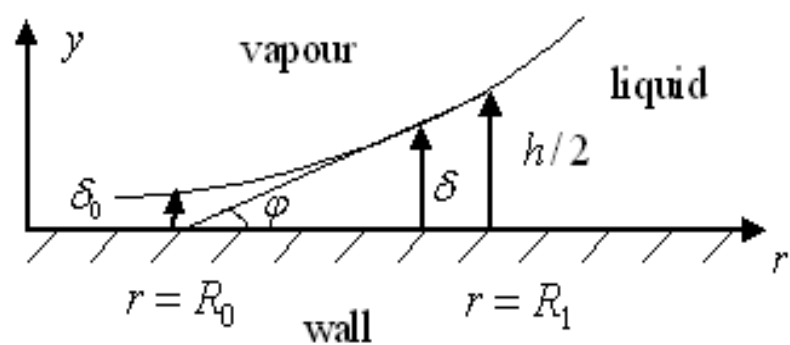

Fig.8. Micro region model.

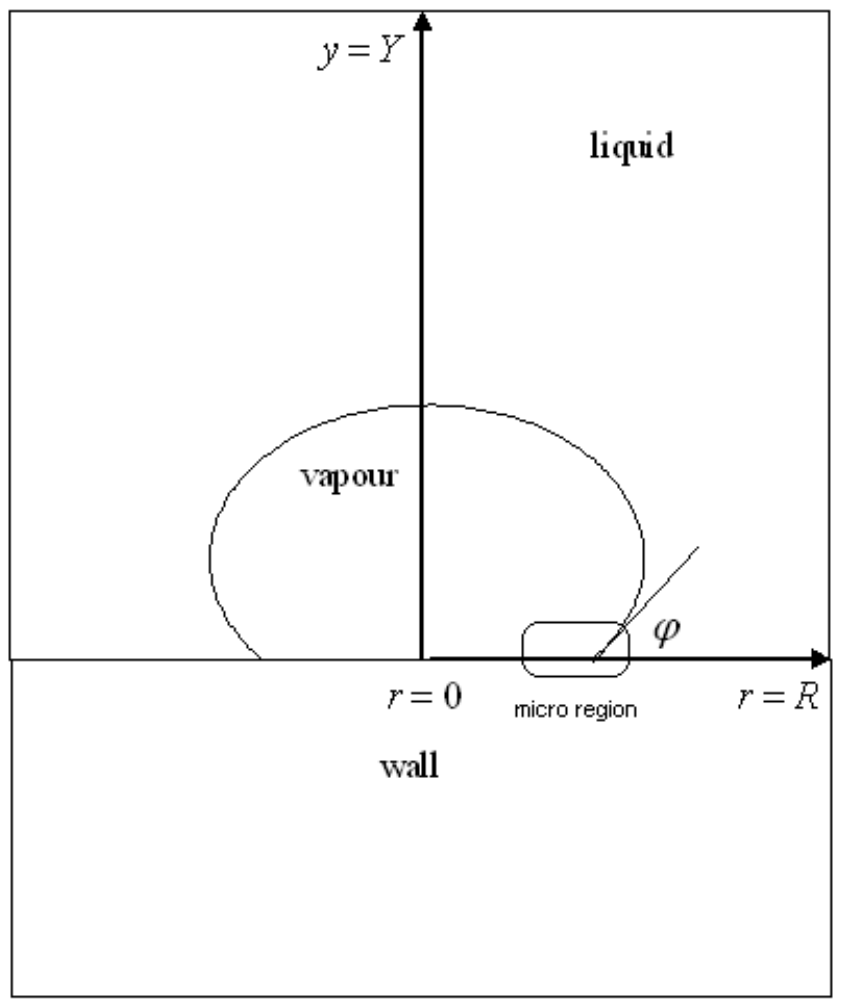

Fig. 9. Macro region model. 


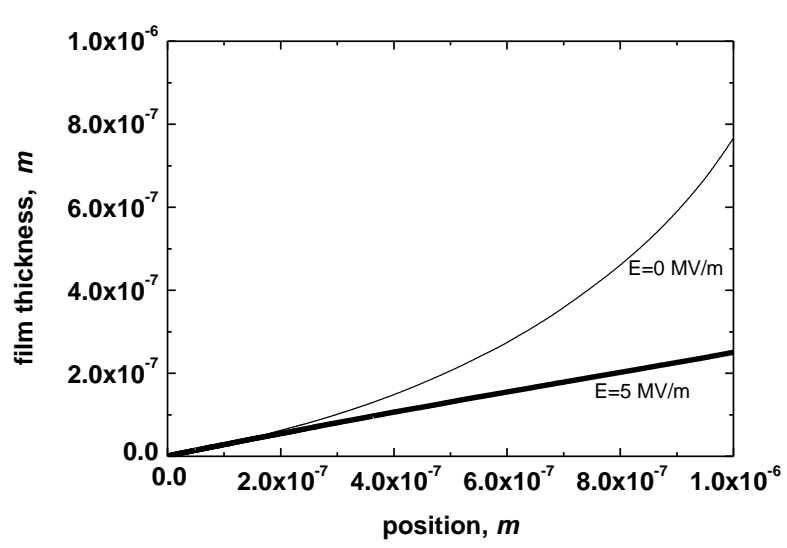

(a)

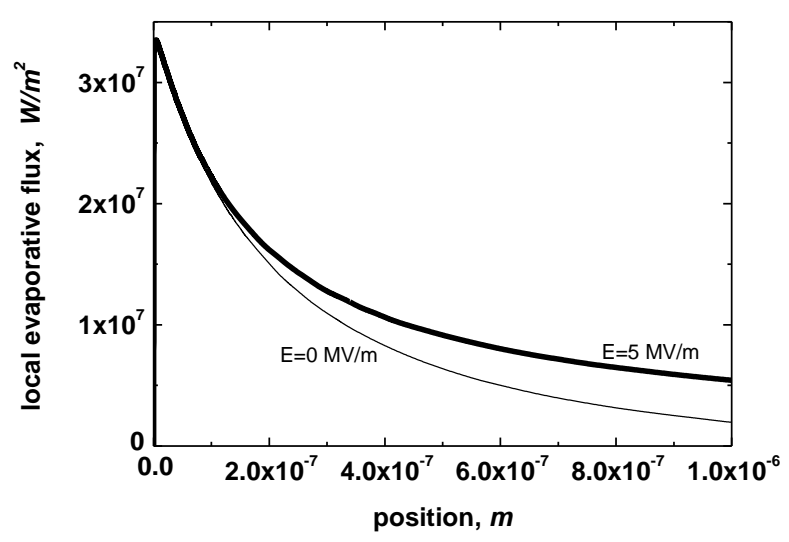

(c)

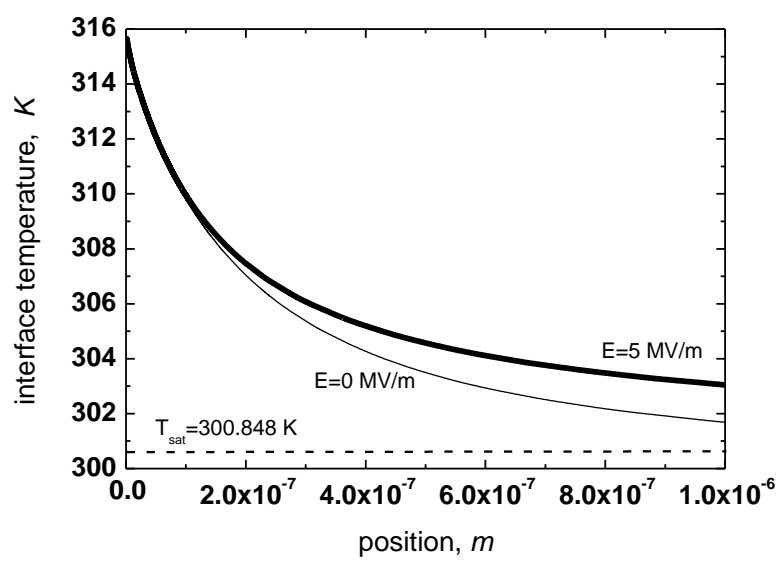

(b)

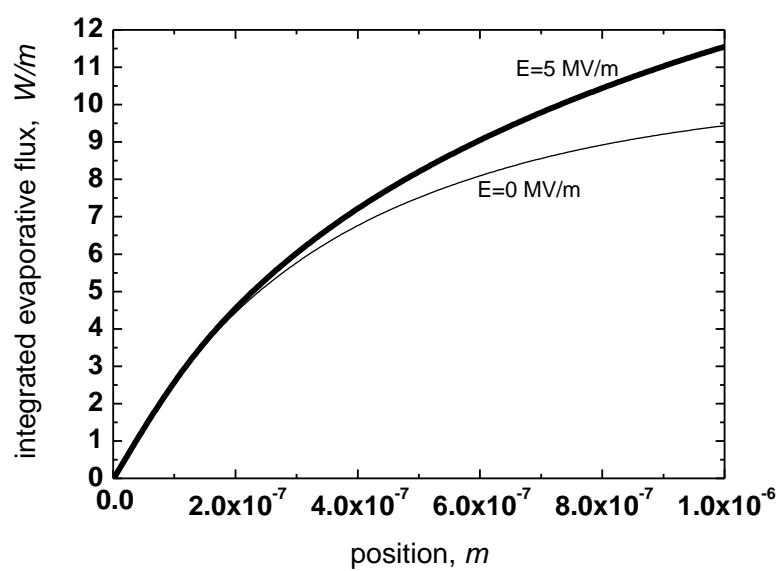

(d)

Fig. 10. Results for the micro region at $\mathrm{t}=1 \mathrm{~ms}$ for $E=0$ and $5 \mathrm{MV} / \mathrm{m}$, wall superheat $15 \mathrm{~K}$ (a) film thickness; (b) temperature at liquid-vapour interface; (c) local evaporative heat flux; (d) integrated evaporative heat flux. 

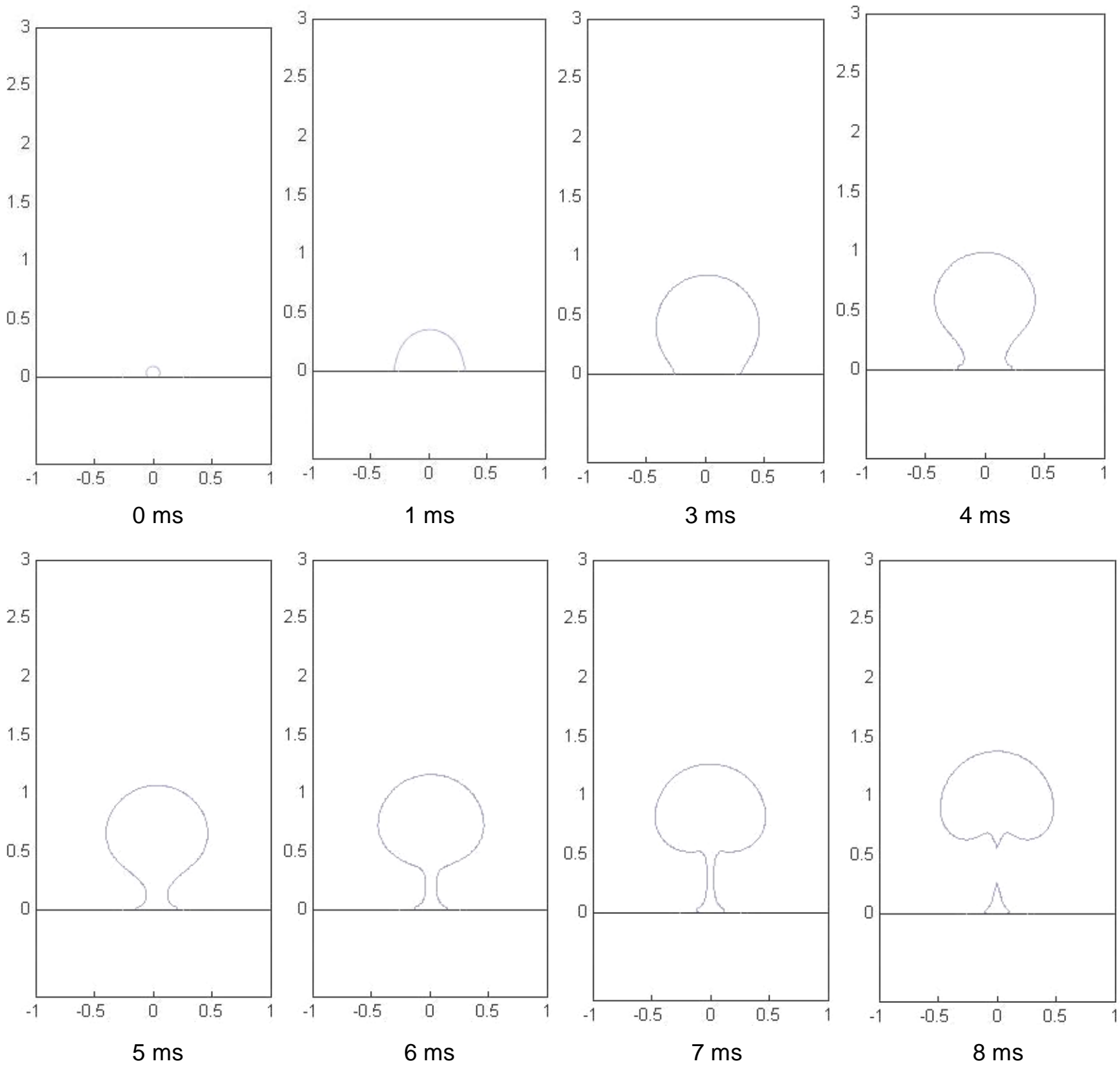

Fig.11. Matched micro-macro region model for bubble growth (a) without an electric field. 

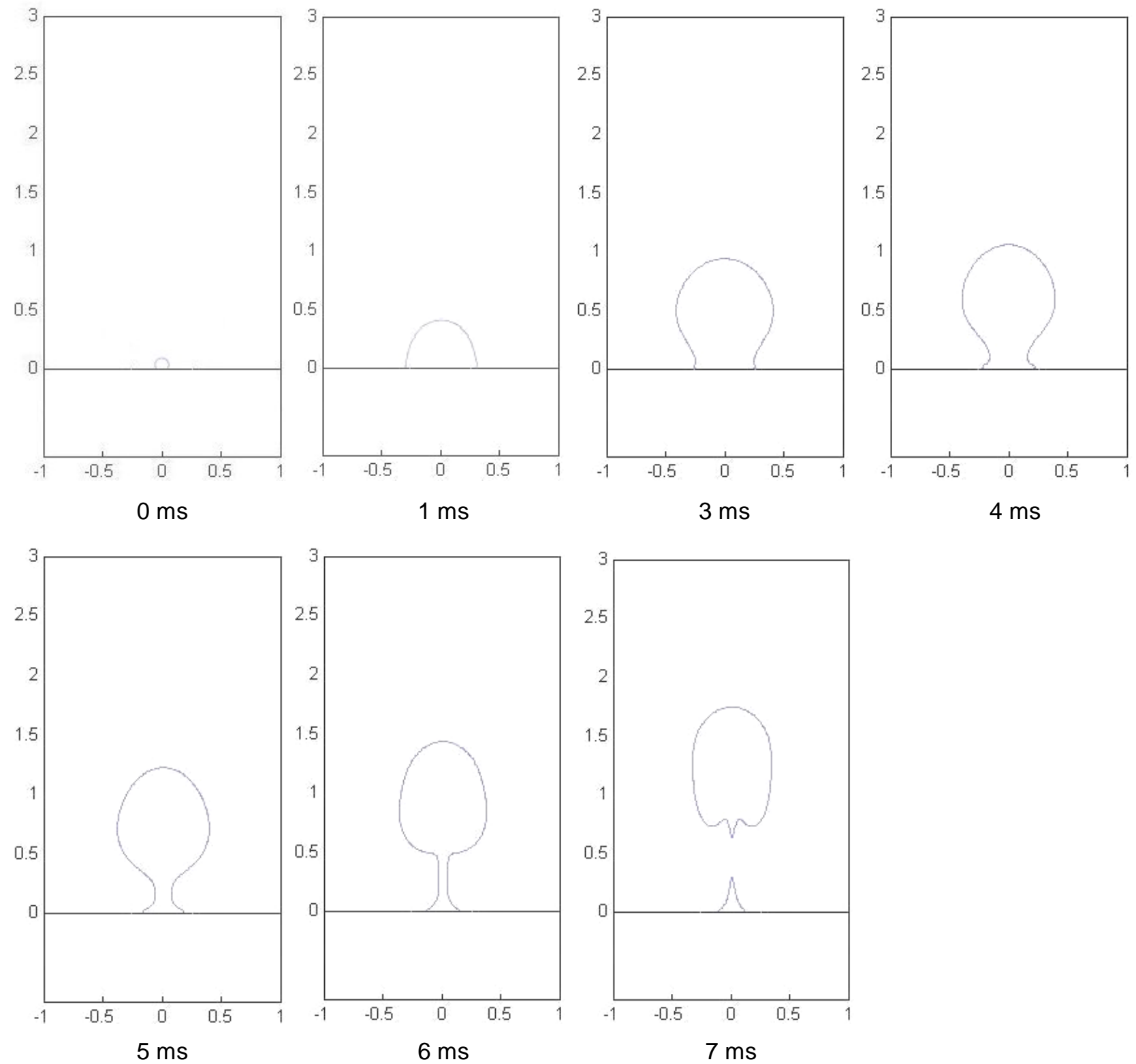

Fig.11. Matched micro-macro region model for bubble growth (b) with an electric field of $5 \mathrm{MV} / \mathrm{m}$. 


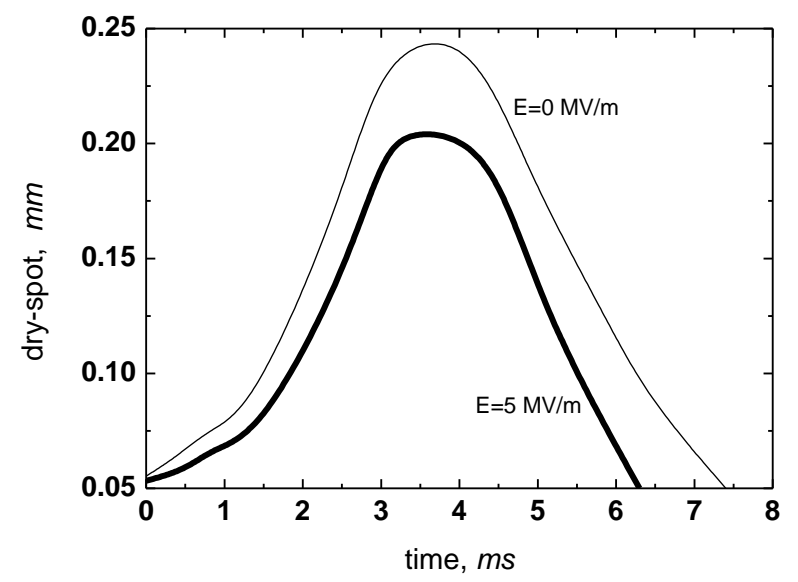

Fig. 12. Evolution of "dry-spot" radius $\mathrm{R}_{0}$ with and without electric field of $5 \mathrm{MV} / \mathrm{m}$ at input heat flux $q_{\text {int }}=100 \mathrm{~kW} / \mathrm{m}^{2}$. 